\title{
ESPECIES NUEVAS Y FILOGENIA DE LAS ABEJAS DE FUEGO, OXYTRIGONA (HYMENOPTERA: APIDAE, MELIPONINI)
}

\author{
Victor H. GonZaleZ ${ }^{*}$ \& David W. RoubiK² \\ ${ }^{1}$ Department of Ecology and Evolutionary Biology, Haworth Hall, 1200 Sunnyside Avenue, \\ University of Kansas, Lawrence, Kansas 66045-7523, USA. vhgonza@ku.edu \\ * Autor responsable de la correspondencia editorial \\ 2 Instituto Smithsonian de Investigaciones Tropicales, Tupper, Apartado 0843-03092, \\ Balboa, Ancón, REPÚBLICA DE PANAMÁ. roubikd@si.edu
}

\begin{abstract}
RESUMEN
Describimos e ilustramos tres especies nuevas de Oxytrigona de Centroamérica y norte de Suramérica, presentamos descripciones de machos y reinas previamente desconocidos, y exploramos la filogenia interna del género. Oxytrigona chocoana sp. nov., del Chocó biogeográfico, es la especie hermana de $O$. daemoniaca; $O$. huaoranii sp. nov. y $O$. isthmina sp. nov., del oriente de los Andes ecuatorianos y del Darién panameño, son mucho más pequeñas que su especie hermana, $O$. mellicolor. Oxytrigona huaoranii presenta caracteres inusuales tales como el fémur anterior corto, con el margen inferior fuertemente carenado, y el área basal del propódeo estriada. El macho de $O$. isthmina se diferencia principalmente de $O$. mellicolor por el gonostilo de la genitalia mucho más curvo y ensanchado apicalmente. También describimos los machos de $O$. daemoniaca y $O$. mediorufa, y el macho y la reina de $O$. mellicolor. El estatus taxonómico de $O$. medioru $f a$ es revisado; según como la entendemos en este trabajo, esta especie se encuentra únicamente desde México hasta El Salvador. Un solo árbol fue obtenido para las especies de Oxytrigona, a partir del análisis cladístico de 18 caracteres morfológicos y cinco de coloración del cuerpo, el cual no apoya la monofilia de los gruposmulfordi y tataira. Las variaciones encontradas en la forma del grádulo y del $m$ a rgen distal del sexto esterno de la obrera, fueron útiles en el análisis taxonómico. Estos caracteres no han sido usados en la sistemática de Meliponini, y esperamos llamar la atención y promover su uso en futuros análisis filogenéticos. También presentamos una clave para la identificación de las especies.
\end{abstract}

Palabras Clave: Abejas sin aguijón, Centroamérica, esterno seis, sistemática

\begin{abstract}
We describe and illustrate three new species from Central America and northern South America, present descriptions for previously unknown males and queens, and explore the internal phylogeny of Oxytrigona. Oxytrigona chocoana sp. nov., the sister species of $O$. daemoniaca, is from the Chocó biogeographic region; $O$. huaoranii sp. nov., and $O$. isthmina sp. nov., from the Eastern Andes of Ecuador and Darién (Panamá), are much smaller than their sister species, O. mellicolor. Oxytrigona huaoranii exhibits unusual characters including a short fore femur with carinate inferior margin, and
\end{abstract}


striated basal propodeum. The male of $O$. isthmina primarily differs from $O$. mellicolor in having genitalia with an apically enlarged and strongly bent gonostylus. We also described the males of $O$. daemoniaca and $O$. mediorufa, and the male and queen of $O$. mellicolor. The taxonomic status $O$. mediorufa is revised; as here understood, this species is distributed only from Mexico to El Salvador. We obtained a single tree for Oxytrigona in a cladistic analysis of 18 morphological and five body coloration characters, which did not support the monophyly of the mulfordi and tataira groups. We also found variation in the gradular and distal margin shapes of the worker sixth sternum, which were useful in the taxonomic analysis. Such characters have not yet been used in the systematics of Meliponini, and we hope to draw more attention to and encourage future phylogenetic studies using these characters. We also present an identification key for the species.

Key Words: Stingless bees, Central America, sixth sternum, systematics

\section{INTRODUCCIÓN}

El propósito de este trabajo es describir tres especies nuevas de Oxytrigona (Cockerell, 1917) de Centroamérica y norte de Suramérica, presentar descripciones de machos y reinas previamente desconocidos, y explorar la filogenia interna del género. Las ocho especies previamente conocidas de Oxytrigona se distribuyen desde el sur de México hasta Brasil (Michener 2007). Las obreras de Oxytrigona tienen glándulas mandibulares que secretan una sustancia que contiene principalmente ácido fórmico, el cual usan en la defensa de sus nidos. Esta sustancia es depositada cuando las abejas muerden la piel, produciendo una quemadura vesicante o con ampollas, que puede durar por varios días; por esta razón, Oxytrigona es comúnmente conocida como abeja de fuego o cagafuego (Roubik et al. 1987).

También examinamos caracteres morfológicos de obreras y machos que son útiles para explorar la filogenia de Oxytrigona, y presentamos una clave para la identificación de las especies.

\section{MATERIAL Y MÉTODOS}

\section{Descripción taxonómica}

Las medidas morfológicas y términos usados son los propuestos por Michener (2007). Los dibujos, medidas y observaciones se realizaron bajo un estéreo microscopio Wild modelo M8 con cámara lúcida. Las abreviaciones usadas en las descripciones son: F, S, T, DO, y DP para flagelómero antenal, esterno y tergo metasomal, diámetro del ocelo medio y diámetro de un punto del tegumento, respectivamente; las dos últimas medidas son usadas como medidas relativas de la longitud de los pelos y puntuación del tegumento. Las medidas son dadas con su error estándar. 


\section{Filogenia}

Para buscar caracteres morfológicos que pudieran ser usados en la filogenia de Oxytrigona, al menos dos obreras de cada especie fueron aclaradas completamente en $\mathrm{KOH}$ al $10 \%$ por $2-3$ horas, y luego disectadas bajo el estéreo microscopio. No usamos este procedimiento con machos porque no tuvimos acceso a suficientes especímenes, ni a los machos de todas las especies. La matriz de datos fue construida en Winclada (Nixon 1999) y luego analizada con Nona, usando los comandos $w h^{*}$ y max* (Goloboff 1993). Todos los caracteres fueron considerados no aditivos, no ordenados, y del mismo peso, para permitir su libre reversión y examinar posibles hipótesis de sus relaciones evolutivas; por lo tanto, el estado de caracter 0 en la Tabla 1 , no necesariamente indica una plesiomorfía. Los árboles fueron visualizados con Winclada (Nixon 1999, optimización lenta). Los grupos externos son taxones con los caracteres más plesiomórficos relativos al grupo de estudio, y son usados para determinar la polaridad de cambio de un caracter (e.g., Wiley et al. 1991). Por estas razones usamos a Trigona (Trigona) amalthea (Olivier) y Partamona (Partamona) peckolti (Friese) como grupos externos, los cuales son representantes de taxones aparentemente cercanos y distantes a Oxytrigona, de acuerdo con la hipótesis filogenética de Meliponini de Michener (1990). Además de los machos descritos en este trabajo, los machos de las siguientes especies fueron estudiados: Oxytrigona obscura, $O$. tataira y $O$. aff. mulfordi. Las siguientes abreviaciones, L, CI y RI, son usadas para longitud del árbol (i.e., número de pasos), índice de consistencia y retención, respectivamente.

\section{Colecciones Entomológicas}

Examinamos más de 1.000 ejemplares de Oxytrigona; a menos que se indique lo contrario en la sección de material examinado, todos los especímenes estudiados se encuentran en el Laboratorio de Investigaciones en Abejas (LABUN), Departamento de Biología, Universidad Nacional de Colombia, Bogotá (G. Nates). Otras colecciones consultadas, así como los acrónimos usados son:

AMNH American Museum of Natural History, Nueva York, USA (J. Rozen).

CIB Colección de entomología de la Corporación de Investigaciones Biológicas, Medellín (D. Sierra).

MEFLG Colección del Museo de Entomología "Francisco Luis Gallego", Universidad Nacional de Colombia, Medellín (A. Smith).

ICN Instituto de Ciencias Naturales, Museo de Historia Natural, Bogotá (F. Fernández).

PUCE Pontificia Universidad Católica del Ecuador, Quito (G. Onore).

RPSP Departamento de Biología, Faculdade de Filosofia, Ciências e Letras de Ribeirão Preto, Universidade de São Paulo, Brasil (J.M. Camargo).

STRI Smithsonian Tropical Research Institute, Panamá (D. Roubik). 
Gonzalez \& Roubik: Especies nuevas y filogenia de las abejas de fuego

SEMC Snow Entomological Division, Natural History Museum, University of Kansas, Lawrence, KS, 66045-7523, USA (Z. Falin).

USNM National Museum of Natural History, Washington DC, USA (D. Furth).

\section{RESULTADOS}

\section{Descripciones taxonómicas}

\section{Oxytrigona daemoniaca (Camargo, 1984)}

(Figs. Obrera: 1, 2, 7, 59; macho: 22, 23, 30-32, 43, 47, 49)

Oxytrigona tataira daemoniaca Camargo, 1984, Por designación original. Holotipo y cinco paratipos de la casta obrera en RPSP. Localidad Tipo: Sasaima, Cundinamarca (Colombia).

Roubik 1983: 330 [como O. obscura; biología de nidificación]

Roubik et al. 1987: 1080 [química de las secreciones glandulares]

Roubik 1989: 416 [Fig. 213]

Roubik 1992: 518 [nuevo estatus, claves, distribución en Panamá (Fig. 31.11g)]

Griswold et al. 1995: 684 [lista de especies]

Bernal \& Ervik 1996: 689 [registro floral]

Nates-Parra 1996: 184 [lista de especies]

Diagnosis. Basitarso posterior con el margen posterodistal ampliamente redondeando (Fig. 2). Área superior de la cara, mesosoma y patas negras; resto de la cara y metasoma amarillo a ferrugíneo claro, contrastando con el resto del cuerpo. F2 con un pelo largo (< diámetro F2) y simple.

Obrera. $(n=5)$ Longitud corporal $4.7 \mathrm{~mm}( \pm 0.1,4.2-5.0)$, longitud del ala anterior $4.8 \mathrm{~mm}$ $( \pm 0.01)$, ancho de la cabeza $2.3 \mathrm{~mm}( \pm 0.01)$. Estructura. Cabeza 1.3x más ancha que larga; distancia interorbital media 1.2x mayor que la inferior; área malar 1.3 DO; clípeo 1.6x más ancho que largo; distancia interalveolar $0.8 \mathrm{x}$ el diámetro alveolar; distancia alveolorbital $3.3 \mathrm{x}$ la distancia interalveolar; distancia interocelar 2.2 DO, ligeramente más grande (1.1x) que la distancia ocelorbital. Escapo 6.8x más largo que ancho, ligeramente más largo que la distancia alveolo-ocelo medio; flagelo + pedicelo casi $2 \mathrm{x}$ más largos que el escapo; pedicelo 1.3x más largo que ancho, 1.2x más largo que el F1, 1.3x más largo que el F2; F1 1.3x más ancho que largo, F2 1.2x más ancho que largo. Gena 1.2x más ancha que el ojo visto de perfil. Mesoescuto 1.4x más ancho que largo, 2.7x más largo que mesoescutelo, mesoescutelo $2.5 \mathrm{x}$ más ancho que largo. Fémur anterior $4.1 \mathrm{x}$ más largo que ancho; basitarso medio $2.5 \mathrm{x}$ más largo que ancho; tibia posterior 2.6x más larga que ancha (Fig. 1), 1.3x más larga que el fémur posterior; basitarso posterior 1.7x más largo que ancho (Fig. 2), su ancho máximo cerca de $0.7 \mathrm{x}$ el ancho máximo tibial. S6 con grádulo ligeramente cóncavo, margen apical del esterno ampliamente redondeada, terminando en una pequeña punta (Fig. 7). Puntuación. Clípeo y área paraocular inferior densamente punteados $(<\mathrm{DP})$, tegumento liso y brillante entre puntos; área supraclipeal e interantenal con algunos puntos dispersos ( $>\mathrm{DP})$; frente 
prácticamente lisa como en el área supraclipeal, puntos más pequeños que en el clípeo, más dispersos en la frente (>2DP); vértice liso, sólo con punteado pilígero espaciado ( $>2 \mathrm{DP})$; área alrededor de los ocelos completamente lisa, sin puntos. Escapo con punteado débil; gena lisa. Mesoescuto liso, puntos ampliamente separados ( $\geq 2 \mathrm{DP}$ ), más densos y fuertes en áreas anterolaterales; mesoescutelo con puntos más densos en los lados ( $\geq 2 \mathrm{DP})$, puntos más grandes que en mesoescuto; mesepisterno y metaepisterno con puntos pilígeros más grandes que en el mesoescuto (1-2 DP), más densos en la base del mesepisterno. Tégula débilmente imbricada. Propódeo liso y brillante, sin puntos; patas lisas y brillantes, sólo con puntuación pilígera. Metasoma en general liso y brillante; T2-T6 y esternos débilmente imbricados. Coloración. Los dos tercios basales de la mandíbula, mitad superior de la frente, vértice, mesosoma y patas negras; gena y área paraocular inferior amarillo quemado; clípeo con dos manchas grandes ferrugíneo oscuro a cada lado de la línea media; pedicelo y mitad superior del escapo negros; flagelo, parte inferior y basal del escapo ferrugíneos. Metasoma amarillo a ferrugíneo claro. Alas levemente ferrugíneas, especialmente en la parte basal del ala anterior; venas amarillas, excepto por $\mathrm{C}$ y $\mathrm{R}$ un poco oscurecidas. Tégula ferrugínea oscura. Pubescencia. Principalmente negra. Labro con pelos oscuros, simples, erectos y largos (> DO). Clípeo, área paraocular inferior y frente con pelos diminutos $(<\mathrm{DO})$, simples, pálidos y decumbentes, más dispersos en la frente; lados del ocelo medio con pelos pálidos, erectos, ramificados y densos, más largos que los pelos del clípeo; dorso del escapo con pelos cortos ( $<$ diámetro F2) y dispersos, parte antero-basal del F2 con un pelo simple, largo $(<$ diámetro F2); gena prácticamente sin pelos, excepto por el área inferior y a lo largo del margen posterior con pelos largos $(\leq \mathrm{DO})$, simples, gruesos, erectos, café oscuros. Mesoescuto, mesepisterno, y metaepisterno con dos tipos de pelos: pelos largos (0.5-1.0 DO), simples, erectos, y oscuros, mezclados entre pelos más cortos, ramificados, decumbentes, y pálidos; pelos erectos más cortos en el mesoescuto, pelos decumbentes más dispersos en el mesepisterno. Mesoescutelo con pelos largos ( $\geq 2 \mathrm{DO}$ ), simples, erectos y oscuros, más densos en los lados. Patas anteriores y medias cubiertas con pelos negros simples, erectos, y gruesos, más largos en la tibia posterior ( $\geq \mathrm{DO}$ ); coxas y trocánteres con pelos ferrugíneos simples, erectos, largos ( $\geq \mathrm{DO}$ ), más densos en el trocánter medio, más largos en la coxa y trocánter posterior. Lados de T1-T4 y margen premarginal de T5 con pelos negros, simples, erectos, cortos $(<\mathrm{DO})$, y dispersos, más largos en T5; margen preapical de T2-T4 escasamente con algunos pelos pálidos simples, decumbentes, muy cortos $(<\mathrm{DO})$, y ampliamente dispersos $(>$ DP); T6 densamente cubierto con pelos negros simples, erectos, largos ( $\geq \mathrm{DO})$, más densos y largos hacia el ápice y lados del tergo. Esternos con mitad apical con pelos negros simples, erectos, y largos como en T6, más densos en los lados; margen apical y área medio preapical de los esternos con algunos pelos pálidos simples, más cortos que los pelos negros.

Macho. $(n=1)$ Como en la obrera, excepto por: longitud corporal $4.5 \mathrm{~mm}$, longitud del ala anterior $4.4 \mathrm{~mm}$, ancho de la cabeza $2.1 \mathrm{~mm}$. Estructura. Cara en perfil mucho más plana que en la obrera, distancia interorbital media $1.4 \mathrm{x}$ la inferior; área malar $0.3 \mathrm{DO}$; labro con margen medioapical emarginada; clípeo $1.5 x$ más ancho que largo; distancia interalveolar 0.7 DO; distancia alveolorbital 1.9x la distancia interalveolar, área interalveolar ligeramente protuberante; distancia interocelar 1.9 DO, 1.6x la distancia ocelorbital. Escapo 3.8x más 
largo que ancho, $0.7 \mathrm{x}$ la distancia alveolo-ocelo medio; flagelo + pedicelo $3.3 \mathrm{x}$ más largos que el escapo; pedicelo 1.4x más ancho que largo, 1.8x más largo que el F1, 0.6x la longitud del F2; F1 2.2x más ancho que largo, 0.4x la longitud del F2, F2 1.2x más largo que ancho. Gena estrecha, la mitad del ancho del ojo en vista lateral. Mesoescuto 1.2x más ancho que largo, 3x más largo que el mesoescutelo, mesoescutelo 2.2x más ancho que largo. Fémur anterior $4 \mathrm{x}$ más largo que ancho; basitarso medio $4.2 \mathrm{x}$ más largo que ancho; tibia posterior 2.8 más larga que ancha (Fig. 22), 1.2x más larga que el fémur posterior; basitarso posterior 1.8x más largo que ancho (Fig. 23). Genitalia y esternos asociados como en las Figs. 30-32, 43, 47, 49. Puntuación. Cara y gena con puntuación más densa que en la obrera, especialmente en la frente. Coloración. Similar a la obrera, excepto por: mitad superior de la frente, vértice, tres cuartos basales de la mandíbula, mitad superior de la gena, mesoescuto y mesoescutelo café oscuro a negro; metaepisterno, propódeo y coxas a basitarsos de todas las patas café oscuros, mediotarsos y distitarsos amarillentos; parte inferior de la gena, clípeo, labro, mitad inferior de la cara y antena amarillo ferrugíneos. Pubescencia. Predominantemente ferrugínea, más larga y densa que en la obrera; frente y área paraocular superior cubierta principalmente de pelos ramificados, semierectos, cortos $(<\mathrm{DO})$ y densos; mandíbula con la cara externa densamente cubierta de pelos simples, decumbentes, y cortos, como en el clípeo, más largos hacia el ápice mandibular; margen inferior de la mandíbula con pelos largos ( $\geq \mathrm{DO})$ como en la gena inferior; F2 sin pelo largo. Mesosoma principalmente cubierto con pelos simples.

Material examinado. PANAMÁ: Colón: 46 , Prov. Portobelo-12 km SW Sta Rita Ridge., 23 Dec 1984, D. Roubik; 14 , Prov. Puerto Pilon, 24 km NE S.R., 23 Jul 1982, D. Roubik, n ${ }^{\circ}$ 82; Darién: 1 으, Prov. El Real-Pijivasal at Legume bush., 16 Feb 1989, D. Roubik; Kuna Yala: 7 , El llano-Carti Road., 24 Apr 1984, D. Roubik; Panamá: 2 9 , Prov. Chepo 30 km, NE., 20 Apr 1984, D. Roubik [STRI]. COLOMBIA: Antioquia: 21 , , Sopetran, en palma coco., Oct 1986, G. Morales [FLG]; 2 9, San Pedro de Urabá, Sul 1982 [FLG]; 4 9 , Rio Claro., May 1985, A. Molina [FLG]; 6 ㅇ, Santa Fé., Ago 1977, A. Molina [FLG]; 3 ㅇ, San Jerónimo, Feb 1978, A. Molina [FLG]; 1 9, Taraza, en compositae., Mar 1975, J. Caro [FLG]; 21 \& , Antioquia, Ene 1977, J. Rincón M [FLG]; 60 9 , Porce., 3 Jun 1997, A. Smith [FLG]; Boyacá: 6 9 , Pto Boyacá, Vda el Pescado., Ene 1969, Restrepo-Mej [ICN]; Chocó: 6 , Rio Sanpichí, B\&E 4B., 25 Mar 1994, R. Bernal; Cundinamarca: 1 , Anapoima, El Consuelo, 700 m alt., 20 Oct 1996, A. Rodríguez; 2 , Apulo., 2 Sep 1976, G. Nates; 2 , mordiendo tronco maracuyá., 26 May 1987; 1 , Arbelaez, vía club el Lago., 24 May 1980, G. Nates; 9 9 , Cachipay, en bellahelena., 9 Abr 1978, NaLiOs [Nates, Liévano \& Ospina]; 1 9 , La Mesa., 2 Jul 1972, J. A. Rodríguez [ICN]; 40 9 , L. M. Arrieta [ICN]; 3 9, Mariquita, Carlos Rocha; 2 , Melgar., 5 Ene 1980, O. Cepeda; 9 ค, Pandi., 12 Mar 1977, G. Nates; 11 \& , Pto. Salgar, en árbol a orilla de carretera, n2., 31 Mar 1983, G. Nates; 2 , Pandi., 12 Mar 1977 [ICN], 10 9 , Quipile, n: 69., 8 Mar 1978, G. Nates; 7 9, Sasaima, n: 2., 14 Ago 1976, Nates-Villa; 14 어, Tocaima, n: 8., 29 Ago 1976; 44 ㅇ, Villeta, n: 13., 5 Mar 1978, G. Nates; 6 , Vergara., 25 sep 1976, G. Nates; 4 ㅇ, Vergara, en nido 7., sep 1976, Nates-Villa [FLG]; Huila: 3 , El Pital, Cementerio, 1 Abr 1994, S. Rodríguez; 12, Rivera, Cementerio, 745 m alt., 30 Mar 1994, G. Nates; 1 \& , Finca Lindoza, Cacaotal, C. Sarmiento; Magdalena: 
3 9, Parque Tayrona., 17 Abr 1976, E. Pereira [ICN]; Santander: 1 , 4 ㅇ, Landazury, Hacienda Las Flores, 540 m, 20 Oct 1980, O. Pinto; 5 ㅇ, 24 Feb 1978, Viver Pin; Tolima: 19 , Ataco, nido., 27 Feb 1980, A. Lievano; 2 9, Cunday., 28 Jul 79, V. Corredor; 2 9, Mariquita, Vda La Guardia, 9: am., 5 Ene 1983, Hilda [ICN].

Distribución geográfica. Suroriente de Costa Rica, Oriente de Panamá hasta Colombia, desde los $150 \mathrm{~m}$ a $1510 \mathrm{~m}$ de altitud. Hasta el momento la localidad más al sur de su distribución es Rivera, Huila (Colombia).

Nidificación. Nidos en cavidades de árboles vivos, raramente en árboles muertos, desde 1.50 m hasta $17 \mathrm{~m}$ sobre el suelo (Roubik 1983; Vergara et al. 1986). La entrada es una abertura o hendidura alargada, demarcada con una resina dura. Presentan un comportamiento de defensa moderadamente agresivo. Nombre común: "miel de candela", candelita", "candela" o "miona" (Roubik 1992, Nates-Parra 1996). Descripciones detalladas de la localización y estructura del nido en Roubik (1983).

Plantas hospederas. De acuerdo con los datos de captura consignados en las etiquetas de algunos especímenes, $O$. daemoniaca visita las siguientes plantas: Impatiens balsamina, Elaeis oleifera, Melicocca bijuga y Vernonia brachiata (Compositae). También se observado colectando polen de las inflorescencias de la palma de tagua o marfil vegetal (Phytelephas seemannii) en la costa Pacífica colombiana (Bernal \& Ervik 1996).

\section{Oxytrigona chocoana sp. nov.}

(Figs. Obrera: 3, 4, 8)

Diagnosis. Se reconoce por el F2 con un pelo largo ( $<$ diámetro del F2) y el basitarso posterior ampliamente redondeado como en $O$. daemoniaca, pero con el tegumento del cuerpo predominantemente negro, incluyendo la cara y el metasoma.

Obrera. Como en $O$. daemoniaca excepto por: longitud corporal $4.7 \mathrm{~mm}$, longitud del ala anterior $4.8 \mathrm{~mm}$, ancho de la cabeza 2.3. Estructura. Área malar subigual al DO; distancia interalveolar 0.6x el diámetro alveolar; distancia alveolorbital 3.8x la distancia interalveolar; distancia interocelar 2.3 DO. Escapo 7x más largo que ancho; pedicelo 1.5x más largo que ancho, 1.7x más largo que el F1, 1.5x más largo que el F2. Gena 1.1x más ancha que ojo en perfil. Mesoescuto 2.5x más largo que el mesoescutelo, mesoescutelo 2.2x más ancho que largo. Fémur anterior 4x más largo que ancho; basitarso medio 2.7x más largo que ancho; tibia posterior 2.8x más larga que ancha (Fig. 3), 1.3x más larga que el fémur posterior; basitarso posterior como en la Fig. 4. S6 con grádulo recto (Fig. 8). Puntuación. Área supraclipeal e interantenal con puntos separados por 1-2 DP; frente ligeramente más punteada que en $O$. daemoniaca; gena con puntos bien separados ( $>2 \mathrm{DP})$, más densos en la gena superior, a lo largo del margen externa del ojo. T3-T6 y esternos débilmente imbricados. Coloración. Predominantemente negra, excepto por la mitad apical de la mandíbula, labro, clípeo, área paraocular hasta la mitad de la frente, antena, gena, y tégula café oscuro; patas 
Gonzalez \& Roubik: Especies nuevas y filogenia de las abejas de fuego
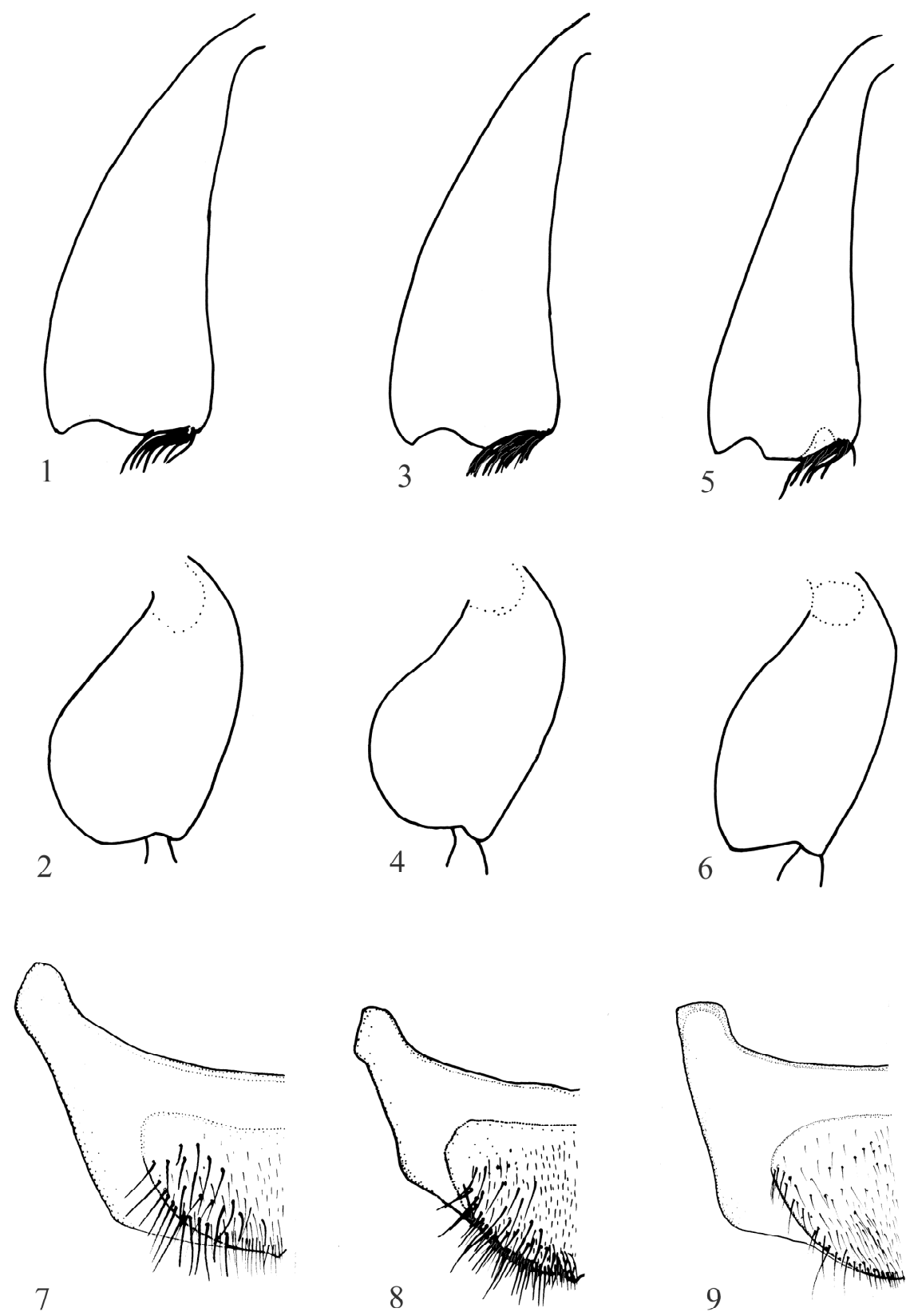

Figuras 1-9

Tibia y basitarso posterior (figuras de arriba y el medio), y esterno seis (abajo) de la obrera de Oxytrigona. $1,2,7=O$. daemoniaca; $3,4,8=O$. chocoana sp. nov.; 5, 6, 9=O. mediorufa . 
anteriores y medias café oscuras a negras; mediotarsos y distitarsos de todas las patas café claros; coxas y mesoescutelo manchados de amarillo. T1-T2 café oscuros. Alas como en $O$. daemoniaca, ligeramente más ferrugíneas en la base y en la celda marginal del ala anterior. Pubescencia. Predominantemente negra. Esternos con pubescencia más densa que en $O$. daemoniaca.

Etimología. Chocoana hace referencia a la distribución de esta especie en el Chocó biogeográfico.

Material tipo. Holotipo, obrera, ECUADOR: Esmeraldas: La Sexta. May 1987. R, Colina. Paratipos. 40 , todos de la misma localidad del holotipo colectados por D. W. Roubik \& G. Onore en 1991, excepto por un ejemplar de San Mateo, colectado el 19 Sep 1956. El holotipo está depositado en el USNM; paratipos en PUCE, SEMC, STRI, y USNM.

Comentarios La obrera de $O$. chocoana y $O$. daemoniaca también se diferencian por la forma del basitarso posterior (Figs. 2 y 4), la forma del grádulo y la densidad de los pelos del S6 (Figs. 7 y 8). Una obrera depositada en el CIB, con la siguiente etiqueta: COLOMBIA, Chocó: 1, Nuquí, Jurubidá, Morro-Mico, jardín, Jama., 4 sep 1995, R. Velez, nº 0101-951120-0181 (no designado como paratipo) en realidad pertenece a $O$. chocoana. Por lo tanto, O. daemoniaca y O. chocoana se encuentran en simpatría, al menos al norte del Chocó colombiano.

\section{Oxytrigona mediorufa (Cockerell, 1913)}

(Figs. Obrera: 5, 6, 9, 58; macho: 24, 25, 39-41, 46, 48, 54)

Trigona flaveola mediorufa Cockerell, 1913

Trigona (Oxytrigona) tataira mediorufa Cockerell, 1913 sensu Schwarz 1948, 1949. Holotipo en AMNH, paratipos en el Museo Británico de Historia Natural (Schwarz 1948). Localidad Tipo: Escuintla, Guatemala.

Ayala 1999: 51 [lista de especies, distribución en México; Fig. 32]

Vit et al. 2004: 3 [meliponicultura en Guatemala]

Diagnosis. Cuerpo predominantemente amarillo a ferrugíneo claro, excepto por las siguientes partes café oscuro a negro: área ocelar, mesoescuto con una mancha triangular (ancho máximo cerca de $1 / 3$ del ancho máximo del mesoescuto), a cada lado de la línea media, extendiéndose desde el margen anterior hasta la axila; lados del mesosoma y patas predominantemente oscurecidos. Registrada únicamente desde el sur de México hasta el Salvador, por la vertiente del pacífico.

Obrera. $(n=16)$ Como en $O$. daemoniaca excepto por: longitud corporal $5.5 \mathrm{~mm}( \pm 0.9$, 5.2-6.2), longitud del ala anterior $5.1 \mathrm{~mm}( \pm 0.5,4.9-5.4)$, ancho de la cabeza $2.6 \mathrm{~mm}( \pm 0.2)$. Estructura. Cabeza 1.4x más ancha que larga; área malar 1.5 DO; clípeo 1.5x más ancho que largo; distancia interalveolar $0.7 \mathrm{x}$ el diámetro alveolar; distancia alveolorbital 3.5x la distancia interalveolar; distancia interocelar $2.3 \mathrm{DO}, 0.8 \mathrm{x}$ la distancia ocelorbital. Escapo $7 \mathrm{x}$ más largo que ancho, del largo de la distancia alveolo-ocelo medio; flagelo + pedicelo $2.2 \mathrm{x}$ 
más largos que el escapo; pedicelo 1.2x más largo que el F2; F1 1.2x más ancho que largo, F2 1.1x más ancho que largo. Mesoescuto 2.6x más largo que el mesoescutelo, mesoescutelo $2.1 \mathrm{x}$ más ancho que largo. Fémur anterior 3.6x más largo que ancho; basitarso medio $2.8 \mathrm{x}$ más largo que ancho; tibia posterior 2.8x más larga que ancha (Fig. 5); basitarso posterior 1.8x más largo que ancho (Fig. 6). S6 con grádulo ligeramente convexo, ápice del esterno ampliamente redondeado, no terminando en punta (Fig. 9). Puntuación. Como en $O$. daemoniaca. Coloración. Principalmente amarilla a ferrugínea clara, excepto por las siguientes áreas café oscuro a negro: margen del tercio basal de la mandíbula, margen denticular rojiza; clípeo con una línea incompleta, delgada, a lo largo del margen distal; sutura epistomal; ápice del escapo y superficie dorsal del flagelo; parte superior de la cara, excepto por manchas amarillas debajo del ocelo medio, lado del ocelo lateral, y área paraocular superior; lados del pronoto; mesoescuto con una mancha negra triangular (ancho máximo cerca de 1/3 del ancho máximo del mesoescuto), a cada lado de la línea media, extendiéndose desde el margen anterior hasta la axila; mesoescutelo con el margen anterior con un mancha oscura en la mitad; resto del mesosoma principalmente negro, algunas veces con una mancha amarilla difusa en la base del mesepisterno; patas predominantemente negras, variablemente manchadas de amarillo en: superficie externa del fémur y tibia de la pata anterior, coxa media, cara interna del basitarso y tarsómeros 2-4 de todas las patas. Pubescencia. Predominantemente amarilla a ferrugínea clara. Labro y mandíbulas con pelos $(0.5-1 \mathrm{DO})$ café oscuros, simples, y gruesos en el margen apical, resto de las mandíbulas con pelos amarillos, más cortos y densos cerca de los dientes. F2 sin pelo; vértice y tórax con pelos amarillo ferrugíneos, pelos del vértice más densos que en $O$. daemoniaca. Vértice con dos tipos de pelos: pelos simples, erectos, largos ( $>$ DO), sobresaliendo de pelos ramificados, decumbentes, más cortos $(<\mathrm{OD})$; T2-T5 con pelos predominantemente negros, T6 con pelos principalmente amarillentos, en general más largos y densos que en $O$. daemoniaca. Esternos con pelos ferrugíneos claros.

Macho. $(n=1)$ Como en la obrera excepto por: longitud corporal $5.5 \mathrm{~mm}$, longitud del ala anterior $5.1 \mathrm{~mm}$, ancho de la cabeza $2.5 \mathrm{~mm}$. Estructura. Cabeza 1.3x más ancha que larga; distancia interorbital media $1.3 \mathrm{x}$ la inferior; área malar corta (1/2 DO); labro con margen medioapical emarginada como en el macho de $O$. daemoniaca. Clípeo $1.4 \mathrm{x}$ más ancho que largo; distancia interalveolar $0.8 \mathrm{x}$ el diámetro alveolar; distancia alveolorbital 1.9x la distancia interalveolar; distancia interocelar 2 DO, casi tan larga como la distancia ocelorbital. Escapo 4.2x más largo que ancho, un poco más corto que la distancia alveoloocelo medio; flagelo + pedicelo más de $4 \mathrm{x}$ más largos que el escapo; pedicelo $1.3 \mathrm{x}$ más ancho que largo, 1.3x más largo que el F1; F2 1.5x más largo que el pedicelo, 2x más largo que el F1, F1 casi 2x más ancho que largo, F2 1.2x más largo que ancho. Mesoescuto 1.2x más ancho que largo, 2.8x más largo que el mesoescutelo, mesoescutelo $2 \mathrm{x}$ más ancho que largo. Fémur anterior 4.1x más largo que ancho; basitarso medio 3.6x más ancho que largo; tibia y basitarso posterior como en las Figs. 24 y 25. Genitalia y esternos asociados como en las Figs. 39-41, 46, 48, 54. Coloración. Escapo, pedicelo y F1 amarillos, base del área malar, junto al margen del ojo, con una mancha negra en forma de media luna; parte superior de la cara con una mancha café oscura a negra restringida al área entre los ocelos laterales y abajo del ocelo 
medio; área postoccipital café oscura a negra. Manchas oscuras mesoescutales un poco más estrechas que en las obreras; pata anterior amarilla, excepto por el fémur (al igual que fémur medio) con manchas difusas café oscuras; coxas y trocánteres medios y posteriores predominantemente amarillos, con superficies externa e interna difusamente manchadas de café oscuro; tibia media negra, excepto por la superficie interna amarillenta y el ápice de la superficie externa con una mancha amarilla difusa; fémur y tibia posterior, basitarsos medio y posterior con superficie externa café oscura a negra, superficie interna amarillenta; resto de tarsómeros en patas medias y posteriores amarillos; S1-S3 difusamente manchados de café oscuro. Pubescencia. En general más larga y densa que en la obrera.

Material examinado. MÉXICO: Chiapas: 1 9, Cacahoatan, Ene 23 1983, R. Murillo [SEMC]; 1 , 3 , Tapachula, Nov 6-15 2003, S. D. Cameron [SEMC]; 2 , 1200 m, Mar 2002, M. Rincón [STRI]; 21 \& , 7 min ENE Tapachula, Jul 1 1955, A. A. Alcorn [SEMC]; 2 , 36.7 km N Tapachula, 440 m, Abr 17 1993, A. Rodríguez, ex. Crotalaria acapulcensis, Physalis gracilis [SEMC]; 1 \& , W. LaBerge [SEMC].

Distribución geográfica. Desde la costa del pacífico de México, cerca de la frontera con Guatemala hasta El Salvador. Schwarz $(1948,1949)$ y Ayala (1999) registraron las siguientes localidades para Centroamérica: México: Chiapas, Finca Buena Vista San Sebastián y Huixtla, Tapachula. Guatemala, además de la localidad tipo: Departamento de Santa Rosa, Chimulilla; Santa Emilia, Pochuta; Moca, Guatalon; Finca Buena vista, San Sebastián y San Salvador en Salvador.

Comentarios. Los registros de O. mediorufa para Colombia (Nates-Parra 1996), Ecuador (Coloma 1986), y Perú (Baumgartner \& Roubik 1989), sugieren que esta especie presenta una distribución disjunta, o que todavía no ha sido colectada en los otros países de Centroamérica. Sin embargo, uno de nosotros (VG) comparó el holotipo (obrera) de O. mediorufa con obreras de esas localidades en Suramérica (incluyendo Bolivia), encontrando diferencias notables entre ellas. Por ejemplo, además de diferencias en el tamaño corporal, estos especímenes suramericanos también difieren en la coloración del área ocelar, tamaño de las manchas oscuras del mesoescuto, pubescencia y puntuación de la frente, pubescencia del S6, y la forma de los basitarsos posteriores. Aunque los especímenes suramericanos son superficialmente similares a $O$. mediorufa de Centroamérica, es posible que estas diferencias morfológicas indiquen la presencia de más de una especie. Esta idea es apoyada porque en las abejas sin aguijón es común encontrar complejos de especies muy relacionadas, en donde las obreras de varias especies son morfológicamente muy parecidas, casi indistinguibles, pero la morfología genital de los machos, o la arquitectura de sus nidos son completamente distintos. Por ejemplo, la genitalia del macho de $O$. isthmina es considerablemente diferente del macho de $O$. mellicolor, aunque las obreras son superficialmente muy parecidas (ver abajo). Sin embargo, no conocemos los machos ni la arquitectura de los nidos de esas especies suramericanas identificadas como $O$. mediorufa; por lo tanto, consideramos que provisionalmente $O$. mediorufa, tal como se entiende en este trabajo, sólo está presente en Centroamérica. 


\section{Oxytrigona isthmina sp. nov.}

(Figs. Obrera: 10-12, 19; macho: 26, 27, 33-35, 44, 51, 52)

Oxytrigona mellicolor Roubik 1992 (parte)

Diagnosis. Cuerpo predominantemente amarillo a ferrugíneo claro como en $O$. mellicolor y $O$. huaoranii. La obrera de $O$. isthmina se diferencia de $O$. mellicolor por su menor tamaño (Fig. 10; ancho de la cabeza $\sim 2.4 \mathrm{~mm}$ ), fémur anterior más corto $(<4 \mathrm{x}$ más largo que ancho), y la forma del basitarso posterior (Fig. 12) y del S6 (Fig. 19). Además del tamaño, el macho de $O$. isthmina también se diferencia de $O$. mellicolor, y de los machos conocidos de otras especies, por la forma del gonostilo de la genitalia, distalmente más curvos y engrosados (compare Figs. 50 y 51). La obrera de $O$. isthmina se diferencia de $O$. huaoranii por el fémur no modificado y el área basal del propódeo lisa.

Obrera. $(n=10)$ Como en $O$. daemoniaca, excepto por: longitud corporal $5.5 \mathrm{~mm}( \pm 0.1$, $5.0-6.1)$, longitud del ala anterior $4.6 \mathrm{~mm}( \pm 0.04,4.3-4.7)$, ancho de la cabeza $2.4 \mathrm{~mm}( \pm$ 0.02, 2.2-2.5). Estructura. Cabeza 1.4x más ancha que larga; distancia interorbital media $1.1 \mathrm{x}$ mayor que la inferior; área malar $1.5 \mathrm{DO}$; distancia interocelar ligeramente más corta (0.9x) que la distancia ocelorbital. Escapo 5.7x más largo que ancho, igual a la distancia alveolo-ocelo medio; pedicelo 1.2x más largo que el F2; F1 y F2 ligeramente más anchos que largos. Mesoescuto 3.1x más largo que el mesoescutelo. Fémur anterior 3.4x más largo que ancho; basitarso medio $2.7 \mathrm{x}$ más ancho que largo; tibia posterior $2.7 \mathrm{x}$ más larga que ancha (Fig. 11); basitarso posterior como en la Fig. 12. S6 con grádulo recto, ápice del esterno ampliamente truncado, casi $0.4 \mathrm{x}$ la longitud entre los bordes externos del grádulo (Fig. 19). Puntuación. Puntuación del clípeo y áreas paraoculares inferiores no tan marcadas como en O. daemoniaca; propódeo con margen basolateral con algunas estriás débiles (presente en un
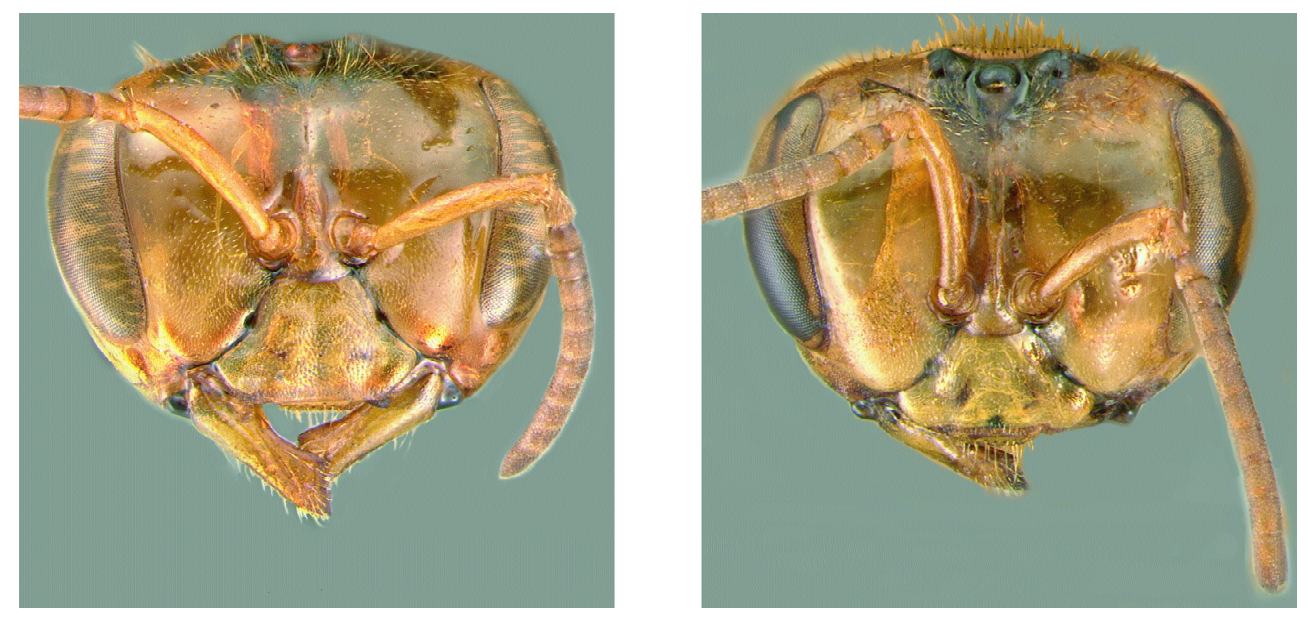

Figura 10

Obreras de O. isthmina sp. nov. (izquierda) y O. mellicolor (derecha). 


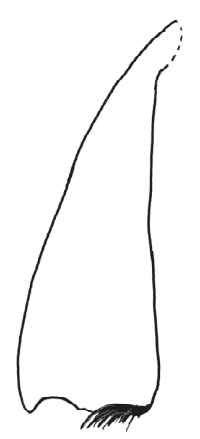

11

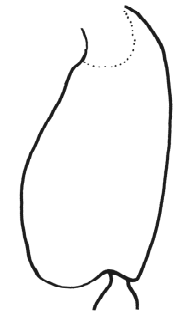

12

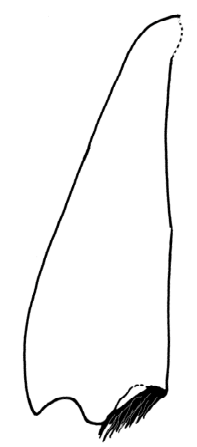

13

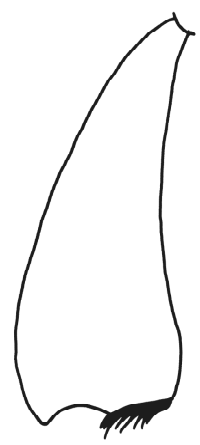

15

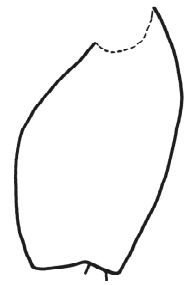

16

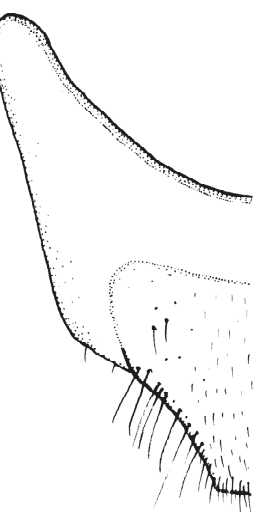

20

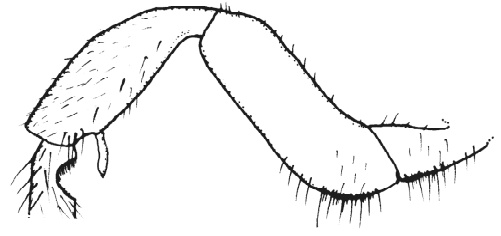

17

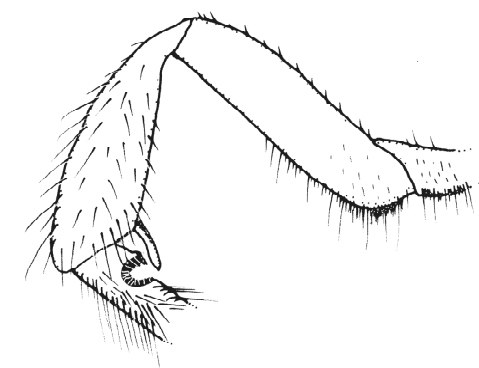

18

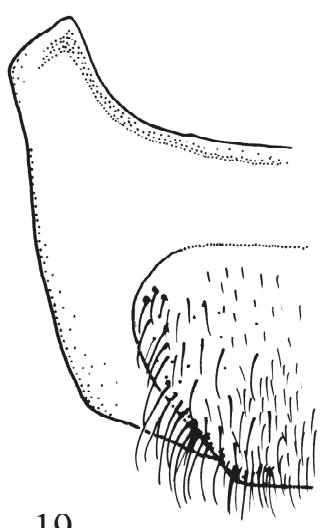

19

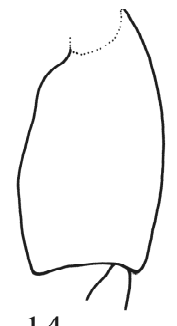

14

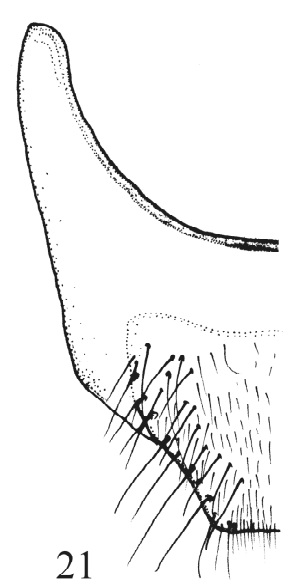

Figuras 11-21

Tibia y basitarso posterior (arriba a la izquierda), fémur y tibia anterior (arriba a la derecha), y esterno seis (abajo) de la obrera de Oxytrigona. 11, 12, $19=$ O. isthmina sp. nov.; 13, 14, 17, $20=O$. huaoranii sp. nov.; $15,16,18,21=$ O. mellicolor. 


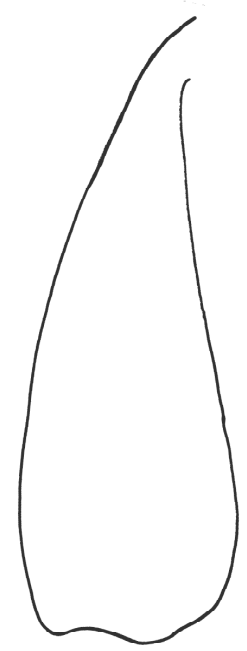

22

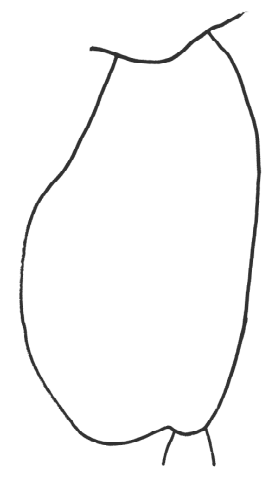

23

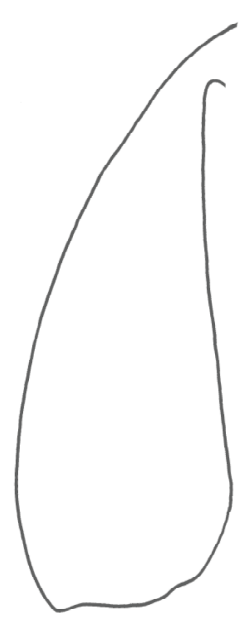

24

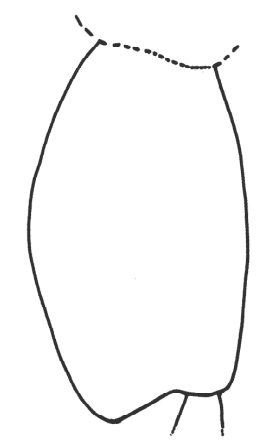

25

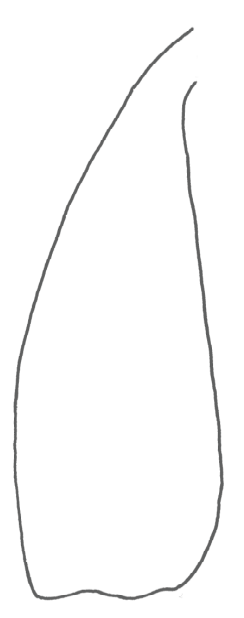

26

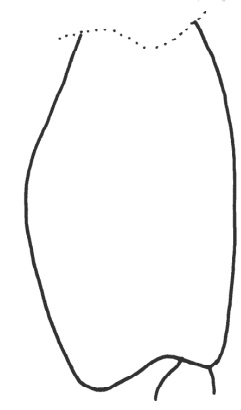

27
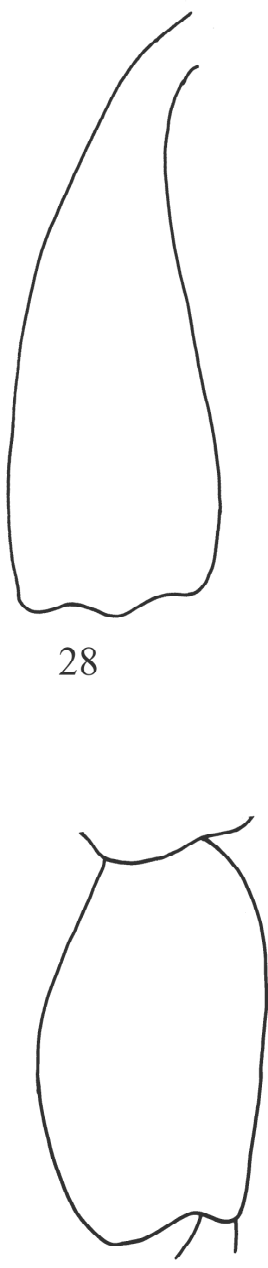

29

Figuras 22-29

Tibia (arriba) y basitarso (abajo) posterior del macho de Oxytrigona. 22, $23=$ O. daemoniaca; $24,25=$ O. mediorufa; $26,27=O$. isthmina sp. nov.; 28, $29=$ O. mellicolor. 
paratipo). Coloración (Variación de paratipos en paréntesis). Amarillo ferrugíneo claro, excepto por las siguientes partes café oscuro a negro: mandíbula en el margen basal y apical; clípeo en el margen apical (pequeña mancha medioapical) y a cada lado de la línea media; superficie dorsal del flagelo; área interocelar y abajo del ocelo lateral (a lo largo de la línea frontal); mancha difusa en el área ocelorbital; área postoccipital. Vientre y lados del mesepisterno; alrededor del lóbulo pronotal; margen anterior del mesoescuto (algunas veces con manchas difusas café oscuras pequeñas $[<\mathrm{OD}]$, uniformemente distribuidas); mitad apical del metaepisterno; área basal y posterior del propódeo (mancha amarilla difusa en el centro del área posterior hasta propódeo completamente amarillento); superficie exterior de la coxa media (mancha difusa café oscura sobre la superficie exterior de la corbícula en la tibia posterior). Tergos metasomales en general un poco más ferrugíneos que el resto del cuerpo. Tégula, venas y estigma amarillo ferrugíneo claro; alas hialinas, ligeramente más coloreadas de amarillo en la mitad basal. Pubescencia. Amarillo ferrugínea clara; F2 sin pelo largo. Metasoma en general con pelos más largos y densos que en $O$. daemoniaca.

Macho. $(n=1)$ Como en la obrera, excepto por: longitud corporal $4.8 \mathrm{~mm}$, Longitud del ala anterior $4.5 \mathrm{~mm}$, ancho de la cabeza $2.1 \mathrm{~mm}$. Estructura. Cabeza 1.2x más ancha que larga; ojos convergentes abajo, distancia interorbital media 1.2x más grande que la inferior; área malar más angosta que en obrera, casi $0.5 \mathrm{DO}$; clípeo $1.5 \mathrm{x}$ más ancho que largo, convexo en perfil, medioapicalmente deprimido; distancia interalveolar ligeramente más pequeña que el diámetro alveolar; distancia alveolorbital 1.6x la distancia interalveolar; distancia interocelar $2.4 \mathrm{DO}, 1.5 \mathrm{x}$ la distancia ocelorbital; cara deprimida a lo largo de la línea media, arriba del alveolo antenal, área supraclipeal protuberante en el centro. Escapo 3.9x más ancho que largo, $0.9 \mathrm{x}$ la distancia alveolo-ocelo medio; flagelo + pedicelo 3.2x más largo que el escapo; pedicelo 1.2x más ancho que largo, 1.4x más largo que el F1; F2 1.4x más largo que el pedicelo; F1 casi 2x más ancho que largo, F2 casi tan ancho como largo. Mesoescuto 2.9x más largo que el mesoescutelo; mesoescutelo $2.4 \mathrm{x}$ más ancho que largo. Fémur anterior 3.5x más largo que ancho; basitarso medio 3.7x más largo que ancho, estrechándose hacia el ápice, $0.7 \mathrm{x}$ la longitud de la tibia media. Tibia posterior 2.7x más larga que ancha (Fig. 26), 1.3x más larga que el fémur posterior; basitarso posterior 1.7x más largo que ancho (Fig. 27). Genitalia y esternos asociados como en las Figs. 33-35, 44, 51, 52. Puntuación. Cabeza más densamente punteada que en la obrera, especialmente en la frente y gena.Coloración. Como en obrera.Pubescencia. Cabeza con pelos más largos y densos que en la obrera; mesosoma y metasoma con pelos más largos y dispersos.

Etimología. El nombre de esta especie hace referencia a su distribución en el Istmo de Panamá.

Material tipo. Holotipo, obrera, PANAMÁ: Darién: El real-Pijivasal at 16 legume bush, 16 Feb 1989, D. Roubik. Paratipos. 1 2 , Parque Nacional Darién, Pirre Estación Rancho frío, 21 Mar-4 Abr 2000, Trampa Malaise, Cambra, Santos, Bermudez; 7 9 , Garachine, 5 km S, 20 Nov 1998, D. Roubik; 1 , 180 km E Bayano, 4 Nov 1982; 1 , 2 km W Canglon, 15 May 1980; 1 ' , Cana Biological Station, 530 m, 745'18'N, 7741'6”W, 10 Jun 1996, J. Ashe, R Brooks, SM16683. Colón: 1 ㅇ, Prov, Sabanita 15 km E, Santa Rita ridge, 22 Jul 1981, D. Roubik. El holotipo se encuentra en el USNM; paratipos en el SMEC, STRI, y RPSP. 
Gonzalez \& Roubik: Especies nuevas y filogenia de las abejas de fuego
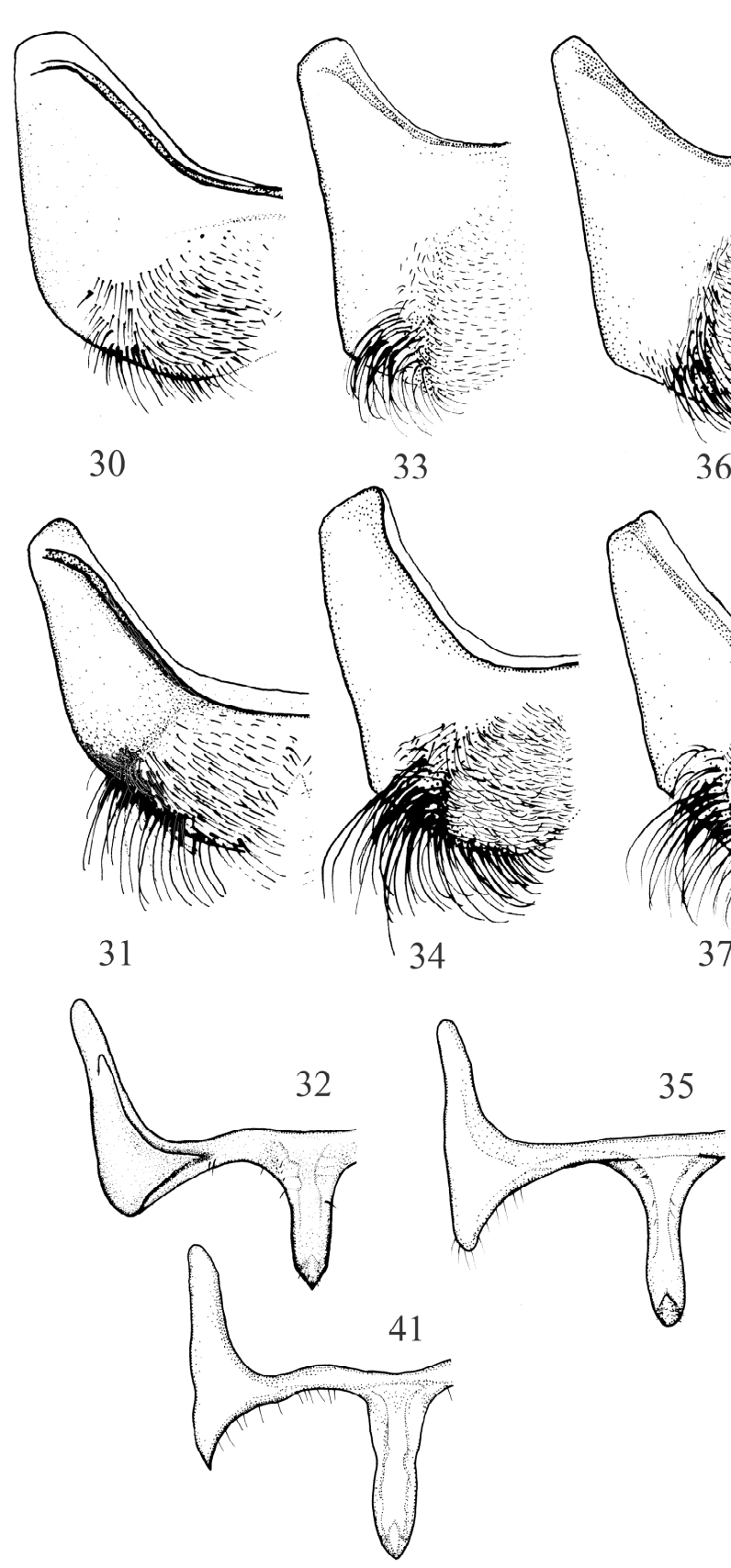

Figuras 30-42

Esternos cinco (arriba), seis (medio) y siete (abajo) del macho de Oxytrigona. $30-32=O$. daemoniaca; 33-35=O. isthmina sp. nov.; 36-38=O. mellicolor; 39-41=O. mediorufa $; 42=O$. mulfordi . 
Comentarios En la colección del SEMC hay por lo menos 100 obreras del Ecuador, la mayoría colectadas en Esmeraldas (Pacífico) y río Palenque, Pichincha, al oriente de los Andes. Estos ejemplares presentan un tamaño corporal intermedio entre $O$. isthmina y $O$. mellicolor; en ausencia de machos, estos especímenes no fueron situados en ninguna de estas especies.

Oxytrigona huaoranii sp. nov.

(Figs. Obrera: 13, 14, 17, 20, 57)

Diagnosis. Cuerpo amarillo ferrugíneo claro como en $O$. isthmina y $O$. mellicolor, pero se diferencia fácilmente de estas especies por el fémur anterior mucho más corto $(\sim 3.3 \mathrm{x}$ más largo que ancho), con el margen inferior fuertemente carenado, y el área basal del propódeo estriada.

Obrera. $(n=8)$ Como en $O$. isthmina, excepto por: longitud corporal $4.8 \mathrm{~mm}( \pm 0.08$, $4.6-5.2)$, longitud del ala anterior $4.4 \mathrm{~mm}( \pm 0.04,4.2-4.5)$, ancho de la cabeza $2.4 \mathrm{~mm}$ ( \pm 0.01, 2.3-2.4). Estructura. Distancia interorbital media 1.2x mayor que la inferior; área malar 1.7 DO; clípeo 1.7x más ancho que largo; distancia interalveolar 1.1x el diámetro alveolar; distancia alveolorbital 2.4x la distancia interalveolar; distancia interocelar $2 \mathrm{DO}$. Área supraclipeal, en perfil, menos protuberante que en $O$. isthmina a lo largo de la línea media. Pedicelo 1.2x más largo que ancho, del largo del $\mathrm{F} 1$, ligeramente más corto que el F2; F1 y F2 ligeramente más largos que anchos. Mesoescuto 2.5x más largo que el mesoescutelo, mesoescutelo $2 \mathrm{x}$ más ancho que largo. Fémur anterior $3.3 \mathrm{x}$ más largo que ancho, con borde inferior fuertemente carenado (Fig. 17); basitarso medio 2.3x más ancho que largo; tibia posterior 2.9x más larga que ancha (Fig.13), 1.4x más larga que el fémur posterior; basitarso posterior como en la Fig. 14. S6 con grádulo cóncavo medialmente, ápice del esterno truncado, aproximadamente $0.3 \mathrm{x}$ la distancia entre los bordes externos del grádulo (Fig. 20). Puntuación. En general como en $O$. isthmina, excepto por la puntuación pilígera de la frente, arriba del área supraclipeal, más fina y densa (1-2 DP); base del propódeo con estrías diagonales fuertes que nacen desde el margen anterior hasta cerca de la línea media, dejando un área transversal lisa; tegumento entre estrías liso y brillante. Coloración. Flagelo antenal, área ocelar, superficies posterior y lateral del propódeo amarillas; celda marginal del ala anterior ligeramente más amarilla que en $O$. isthmina. Pubescencia. En general mucho más corta y dispersa que en $O$. isthmina, excepto por la frente, arriba del área supraclipeal, con los pelos pequeños mucho más densos (1-2 DP).

Etimología. Esta especie es nombrada en honor a la comunidad indígena Huaorani de la región del Napo, en Ecuador. Los Huaorani también son llamados "Los últimos hijos libres del Jaguar", y son conocidos localmente por su carácter bien fuerte.

Material tipo. Holotipo, obrera, ECUADOR: Napo: 1 , Yasuni Nat. Park Est. La Católica, 14-26 Apr 1998. D. Roubik; depositado en el USNM. Paratipos. 55 ㅇ con los mismos datos del holotipo depositados en SMEC, STRI, y PUCE. 
Gonzalez \& Roubik: Especies nuevas y filogenia de las abejas de fuego

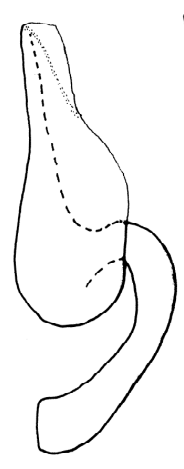

43

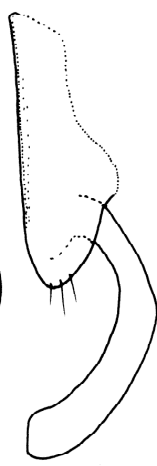

44

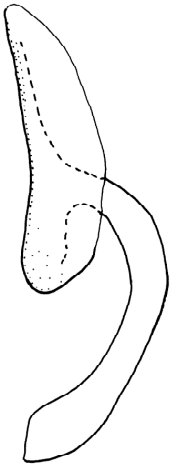

45

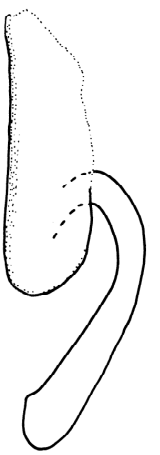

46

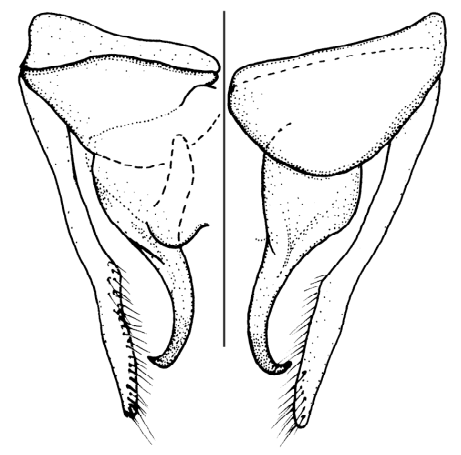

50
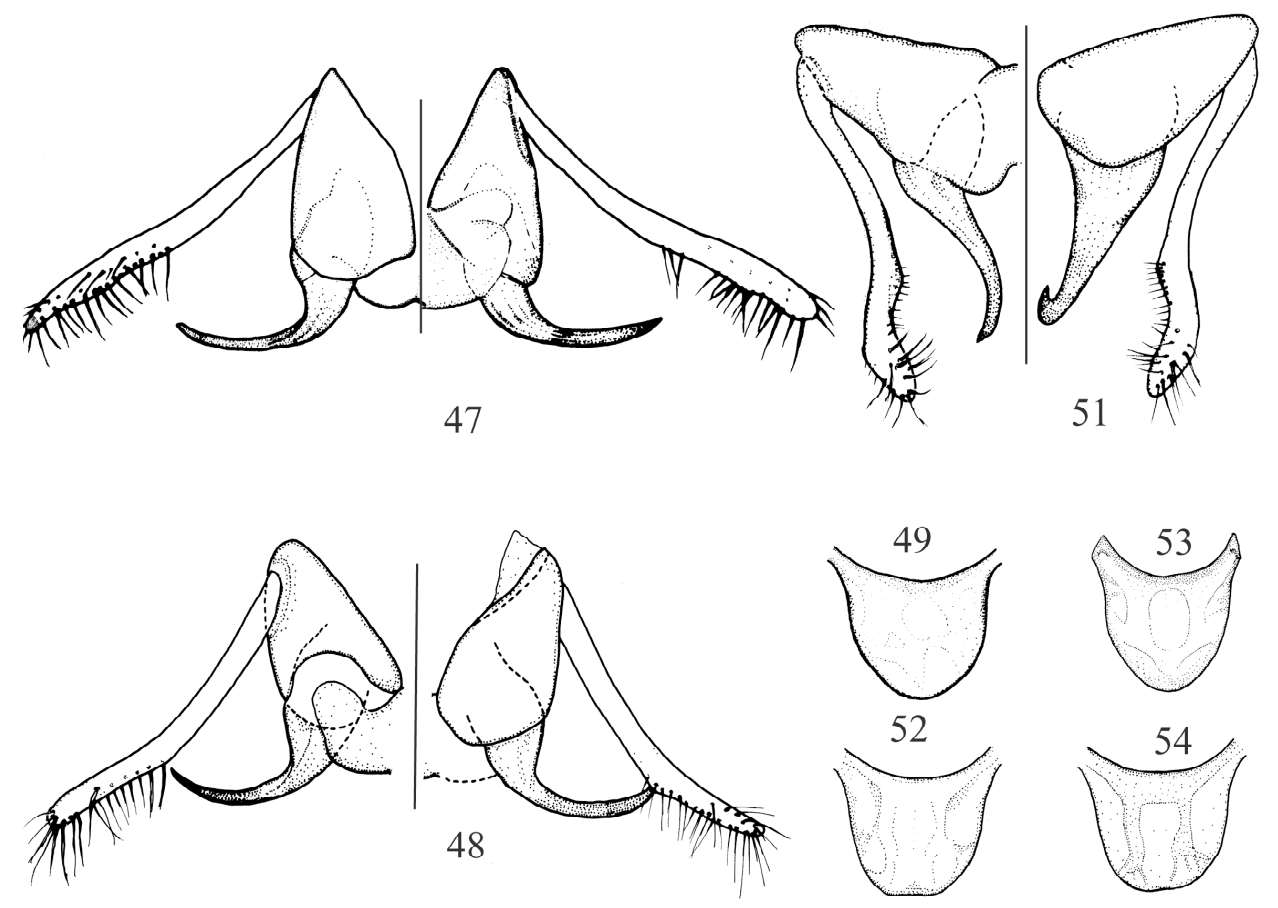

Figuras 43-54

Esterno siete en vista lateral (arriba a la izquierda), cápsula genital en vista dorsal (mitad izquierda) y ventral (mitad derecha), y esterno ocho (abajo a la derecha) del macho de Oxytrigona. 43, 47, 49= O. daemoniaca; 44, 51, $52=$ O. isthmina sp. nov.; 45, 50, $53=$ O. mellicolor; 46, 48, $54=$ O. mediorufa . 


\section{Oxytrigona mellicolor Packard, 1869}

(Figs. Obrera: 10, 15, 16, 18, 21, 55; macho: 28, 29, 36-38, 45, 50, 53, 60)

Trigona (Oxytrigona) tataira mellicolor Packard sensu Schwarz 1948. Holotipo en el Museum of Comparative Zoölogy. Localidad tipo. Holotipo colectado entre Quito y el Río Napo en Ecuador.

Schwarz 1948: 484 [descripción macho, distribución]

Roubik 1983: 330 [biología de nidificación]

Roubik et al. 1987: 1080 [química de las secreciones glandulares]

Rinderer et al. 1988: 496 [bioensayos de extractos cefálicos]

Roubik 1989: 416 [Fig. 213]

Roubik 1992: 518 [nuevo estatus, claves, distribución en Panamá (Fig. 31.11g)]

Griswold et al. 1995: 684 [lista de especies]

Nates-Parra 1996: 184 [lista de especies]

Roubik \& Wolda 2001: 56 [estudio comparativo, abundancia estacional, Panamá]

Pereboom \& Biesmeijer 2003: 43-46 [fisiología, estudio comparativo, tamaño, y color cuerpo]

Diagnosis. Puede ser reconocida por la coloración amarilla a ferrugínea clara del cuerpo, con la membrana del ala hialina, ligeramente coloreada de amarillo. En general es de tamaño corporal más grande y tiene el fémur anterior más alargado que en $O$. isthmina y $O$. huaoranii (Fig. 10; ancho cabeza $\sim 2.5 \mathrm{~mm}$; fémur $>4 \mathrm{x}$ más largo que ancho, Fig. 18). Otros comentarios comparativos de la obrera y el macho de $O$. mellicolor con $O$. isthmina y $O$. huaoranii se encuentran en la diagnosis de estas especies.

Obrera. $(n=15)$ Como en $O$. isthmina excepto por: longitud corporal $6.0 \mathrm{~mm}( \pm 0.08$, $5.2-6.5)$, longitud del ala anterior $5.1 \mathrm{~mm}( \pm 0.03,4.9-5.4)$, ancho de la cabeza $2.5 \mathrm{~mm}( \pm$ 0.01, 2.4-2.9). Estructura. Cabeza 1.3x más ancha que larga; clípeo 1.5x más ancho que largo; distancia alveolorbital 3.2x la distancia interalveolar. Escapo 6.4x más largo que ancho, $0.8 \mathrm{x}$ la distancia alveolo-ocelo medio; pedicelo $1.6 \mathrm{x}$ más largo que ancho, $1.5 \mathrm{x}$ más largo que el F1 y F2, individualmente; F1 y F2 casi 1.2x más anchos que largos. Mesoescuto 2.8x más largo que mesoescutelo, mesoescutelo $2.3 \mathrm{x}$ más ancho que largo. Fémur anterior $4.3 \mathrm{x}$ más largo que ancho (Fig. 18); tibia posterior 2.6x más larga que ancha (Fig. 15); basitarso posterior como en la Fig. 16. S6 con grádulo ligeramente cóncavo, ápice del esterno truncado, 0.4x el ancho gradular (Fig. 21). Puntuación. Como en O. isthmina. Coloración. Área ocelar, áreas ventrolaterales del mesosoma, incluyendo superficies lateral y posterior del propódeo, superficie ventral del fémur posterior, y superficie externa de la tibia posterior, desde completamente amarillos hasta variablemente manchados de café oscuro. Pubescencia. Como en $O$. isthmina.

Macho. $(n=3)$ Como la obrera, excepto por: tamaño corporal 4.8-5.8, longitud del ala anterior 4.5-5, ancho de la cabeza 2.1-2.4. Estructura. Ojos convergentes abajo, distancia interorbital media 1.3x más grande que la inferior; área malar más angosta que en la obrera (0.6 DO); clípeo ligeramente convexo en perfil, medioapicalmente deprimido; distancia 
Gonzalez \& Roubik: Especies nuevas y filogenia de las abejas de fuego
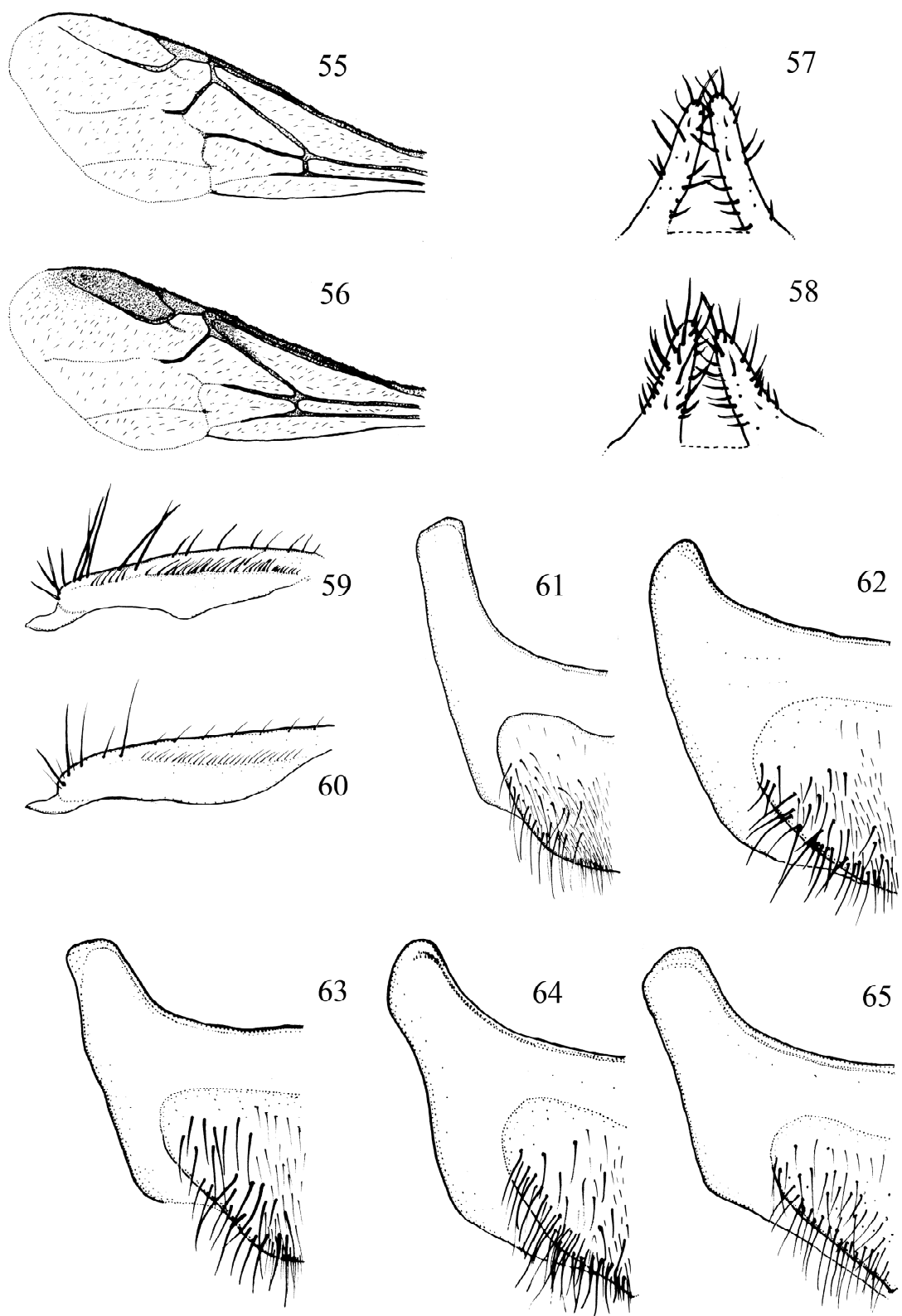

Figuras 55-65

$55,56=$ ala anterior de Oxytrigona mellicolor y $O$. mulfordi; $57,58=$ gonostilos de la obrera de $O$. huaoranii sp. nov. y $O$. mediorufa; $59,60=$ estipe de la probóscide de $O$. daemoniaca y O. mellicolor; $61-65$ = esterno seis de la obrera de O. ignis, O. tataira, O. obscura, O. mulfordi y $O$. flaveola, respectivamente. 
interalveolar ligeramente más pequeña que diámetro alveolar; distancia alveolorbital 1.6x la distancia interalveolar; distancia interocelar 2.4 DO, 1.7x la distancia ocelorbital; cara deprimida a lo largo de la línea media, arriba del alveolo antenal, área supraclipeal protuberante. Escapo 4x más ancho que largo, casi del largo de la distancia alveolo-ocelo medio; flagelo + pedicelo 3.3x más largo que escapo; pedicelo de longitud igual a su ancho, 1.7x más largo que F1; F2 1.3x más largo que pedicelo; F1 casi 2x más ancho que largo, F2 ligeramente más largo que ancho. Mesoescuto $1.2 \mathrm{x}$ más ancho que largo, $3.3 \mathrm{x}$ más largo que mesoescutelo. Fémur anterior 3.7x más largo que ancho; basitarso medio $3.5 \mathrm{x}$ más largo que ancho, estrechándose hacia el ápice; tibia posterior 2.7x más larga que ancha (Fig. 28); basitarso posterior como en la Fig. 29. Genitalia y esternos asociados como en las Figs. 36-38, 45, 50, 53. Puntuación. En general como en la obrera, un poco más densa en la frente. Coloración. Flagelo antenal café oscuro. Pubescencia. Más larga y densa que en la obrera.

Reina. $(n=1)$ Como la obrera, excepto por: longitud corporal $9.6 \mathrm{~mm}$, longitud del ala anterior $5.6 \mathrm{~mm}$, ancho de la cabeza $2.5 \mathrm{~mm}$. Estructura. Cabeza 1.2x más ancha que larga; área malar 1.7 DO. Clípeo 1.6x más ancho que largo; distancia alveolorbital 2.4x la distancia interalveolar; distancia interocelar 1.6 DO, 0.7x la distancia ocelorbital. Escapo casi 6x más largo que ancho, 1.4x más largo que distancia alveolo-ocelo medio; pedicelo 1.7x más largo que ancho, casi 2 x más largo que F1 y F2, individualmente. Mesoescuto 1.8x más ancho que largo, 2.3x más largo que el mesoescutelo. Fémur anterior cerca de $3 \mathrm{x}$ más largo que ancho; basitarso medio $4.6 \mathrm{x}$ más largo que ancho; tibia posterior casi $3 \mathrm{x}$ más larga que ancha, basitarso posterior 2.4x más largo que ancho. Puntuación. Como en la obrera. Coloración. Como en la obrera. Pubescencia. Vértice prácticamente sin pelos, solo con un mechón de pelos largos (>2 DO) y simples detrás de los ocelos. Patas con los pelos en general más densos y largos que en la obrera, especialmente en la pata posterior.

Material examinado. COSTA RICA: Heredia: 1 क , 5 mi E Puerto Viejo, 4-15 Jul 1966, J. B. Karren [SEMC]; Guanacaste: 3 , Santa Rosa Nat. Park, 16 Feb 1973, at water hole, E. M. Barrows [SEMC]; Puntarenas: 1 , Quepos, 13 Feb 1987, G. E. Bohart [SEMC]; 4 , , Esparta, May 1976, G. Fuentes [SEMC]; 2 9, San Vito vicinity, 28 Mar 1973, at UV light, E. M. Barrows [SEMC]; 9 , Gromaco, $34 \mathrm{~km} \mathrm{SE}$ of potrero grande, on rio Coto Brus, $21 \mathrm{Jul}$ 1963,1000 ft., C. D. Michener \& W. Kerfoot [SEMC]; 14 9 , Banco, Tiskita 25 m, 8 21 ' 21" N, 83 8' 6" W, 20-25 Feb 2000, C. D. Michener [SEMC]; San José: 1 9, 1 , Zeledón, San Isidro, 800 m, Feb 1-Apr 1 2002, T. H. Ricketts [SEMC]; 9 9, Río Damitas 14.5 km N. Puerto Quepos 200m., 16 Aug 1962, C. D. Michener \& A. Wille [SEMC, STRI]. PANAMÁ: Chiriquí: 1 9, Prov. Horconcitos-Batipa., 26 Sep 1998 on Mimosa, D. Roubik [STRI]; Colón: 1 y 2 , Santa Rita Ridge, 24 Jul 1982, nest, D. Roubik coll [STRI]; Panamá: 1 reina y 31 , Barro Colorado Island., 7 Oct 1979, D. Roubik coll 14 [STRI]; 2 , Prov. Soberanía Natl. Park Pipeline Road km 8., 10 Mar-15 apr 1991 on carrion, T. Touré coll [STRI]; San Blás: 1 , Pto Obaldía beach S. 100 cc. 1979, D. Roubik, n 5 [STRI]. COLOMBIA: Antioquia: 1 ㅇ, Medellín., 28 Jan 1984, D. Roubik [STRI]; 2 , Taraza, en vuelo., Abr 1971, R. Velez [MEFLG]; 5 9, Currulao., 11 Dic 1970, D. Galeano [MEFLG]; 1 9, en P. Barrio, colec $11 \mathrm{n}^{\circ}$ 60, Feb 1938, Gallego [MEFLG]; 36 9, Porce, 3 Jun 1997, A. Smith [MEFLG]; 


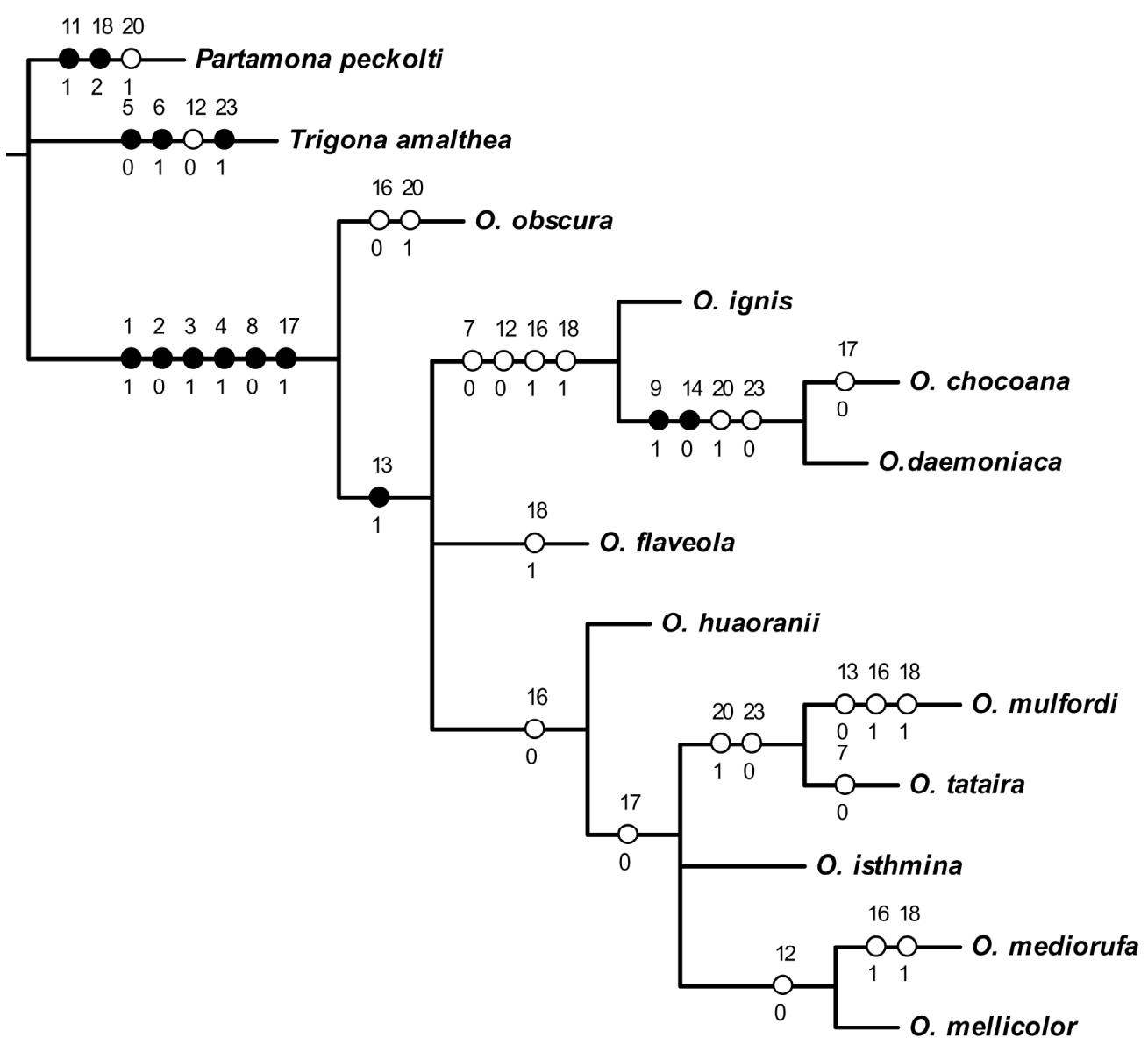

Figura 66

Filogenia de las especies de Oxytrigona. Se obtuvo un sólo árbol parsimonioso $(\mathrm{L}=37, \mathrm{CI}=56, \mathrm{RI}=$ 60) de los caracteres listados en la Tabla 1. Círculos negros indican cambios únicos (sinapomorfías); círculos blancos indican homoplasias; los números de arriba y abajo de cada cambio corresponden al número y estado del caracter. 
2 , Rio Claro, May 1985, A. Molina [MEFLG]; Boyacá: 1 \& , Muzo 20 km SE., 4 Jul 1985, D. Roubik [STRI]; Caldas: 1 \& , La Dorada, Hacienda 3 aires., 14 Ago 1980, L. Cruz; Cesar: 9 9, Serranía de los Motilones., 7 Abr 1977, Ruiz; Cundinamarca: 1 9, Anapoima, El Consuelo, 700 m alt., 20 Oct 1996, A. Rodríguez; 13 , Apulo, en pl: 020-024., 2 Sep 1976, Nates; 1 , Guaduas, vía Honda-Guaduas, 810 m alt., 3 Abr 1983, R. Ospina; 4 , Nilo, vía Pueblo Nuevo, al vuelo, pl: 5, 425 m alt., 25 Nov 1983, LiOs; Chocó: 1 , Nuqui, Jurubidá, Morro-Mico, jardín, Jama., 4 Sep 1995, R. Velez, n 0101-950904-0171 [CIB]; Nariño: 1 ㅇ, Tumaco, en palma africana., Ago 1967, O. Jiménez [MEFLG]; Tolima: 8 9, Mariquita, bosque Municipal, 900 m alt., 19 Abr 1999, V. H. González; 1 , Melgar., 5 Ene 1980, O. Cepeda; 6 ?, Vereda San José, 425 m alt., 5 Abr 1992, C. Sarmiento. ECUADOR: Loja: Sabonilla, Sep 1985, L. Coloma, "miafuego" [SEMC]. VENEZUELA: Portuguesa: 3 , Acarigua, 1981, T. E. Rinderer [SEMC]; 1 9 , Papelón, Finca Paja Brava, 123 m alt., 11 Sep 1997, V. H. González; 1 \& , Guanare, Cavacas, 250 m alt., 12 Sep 1997, G. Nates Parra.

Distribución geográfica. Desde Ecuador, Colombia, y Venezuela hasta Honduras, desde el nivel del mar hasta cerca de $1500 \mathrm{~m}$ de altura. Oxytrigona mellicolor es la especie más ampliamente distribuida del complejo mellicolor, estando en simpatría con $O$. isthmina en el Chocó biogeográfico, y con $O$. huaoranii al oriente de los Andes ecuatorianos. Schwarz (1948) registró las siguientes localidades: Honduras: Tela, Guiamos; Subirana, Departamento de Yoro. Nicaragua: Chontales. Costa Rica: Cache; Hamburg Farm. Panamá: Chiriqui, Volcán de Chiriqui; David; Progreso. Venezuela: Lagunita de Aroa. Coloma (1986), indica las siguientes localidades para Ecuador: Esmeraldas, Quinindé; Sabanilla.

Nidificación. Al igual que $O$. daemoniaca, esta especie construye nidos en cavidades de árboles vivos, entre $1.6 \mathrm{~m}$ a $11 \mathrm{~m}$ del suelo (Roubik 1983, 1992).

Comentarios. La reina descrita tiene el metasoma enormemente hinchado y las alas muy desgastadas, indicando que es una reina fisiogástrica. El S6 de la reina no fue estudiado debido al mal estado en que se encontraba el metasoma.

\section{Filogenia de Oxytrigona}

Caracteres. Los caracteres usados para explorar la filogenia de Oxytrigona fueron los siguientes (A menos que se indique lo contrario, todos corresponden a caracteres de obreras; Tabla 1):

1) Espacio malar: $0=$ estrecho $[\leq 2 \mathrm{x}$ el diámetro máximo del escapo]; $1=$ ancho $[>2.1 \mathrm{x}$ el diámetro máximo del escapo]. 2) Ojos compuestos: $0=$ pequeños $[<0.7 \mathrm{x}$ la distancia máxima entre las márgenes internas de los ojos], $1=$ grandes [ $>0.8 x]$. 3) Puntuación del clípeo: $0=$ puntos pequeños, dispersos ( $\geq 1 \mathrm{DP})$, y superficiales, $1=$ puntos gruesos y densos $(\leq 1 \mathrm{DP}) .4)$ Área paraocular inferior: $0=$ plana en perfil, al mismo nivel con el margen interno del ojo, $1=$ hinchada, por encima del margen interno del ojo. 5) Dientes sobre los $2 / 3$ apicales del margen distal de la mandíbula: $0=$ presentes, $1=$ ausentes. 6) Forma del flabelo de la glosa: $0=$ redondeado [casi tan ancho como largo], $1=$ alargado [más largo que ancho]. 7) Estipes de la probóscide: $0=$ con fila de pelos sobre el margen externo de la superficie ventral (Fig. 59), $1=$ 
sin fila de pelos sobre el margen externo de la superficie ventral (Fig. 60). 8) Pelos erectos a lo largo del margen interno del escapo: $0=$ ausentes, $1=$ presentes. 9) Pelo erecto sobre el F2: $0=$ ausente, $1=$ presente. 10 ) Coloración de la celda marginal: $0=$ del mismo color del resto del ala (Fig. 55), $1=$ oscurecida (Fig. 56). 11) Pelos sobre el propódeo: $0=$ ausentes, $1=$ presentes. 12) Longitud fémur anterior: $0=$ largo [ $\geq 4.1 \mathrm{x}$ más largo que ancho, Fig. 18], $1=$ corto $[\leq 4 \mathrm{x}$, Fig. 17]. 13) Longitud de la proyección media del $S 7$ del macho: $0=$ corta $[\leq 2 \mathrm{x}$ más ancho que largo, Fig. 42], 1 = larga [ $\geq 2.1 x$, e.g., Fig. 35]. 14) Borde posterodistal del basitarso posterior: $0=$ ampliamente redondeado [Figs. 2, 4], $1=$ no ampliamente redondeado [e.g., Fig. 6]. 15) Color de los pelos del vértice: $0=$ negro, $1=$ amarillo. 16) Margen medioapical del S6: $0=$ truncado [Figs. 19-21, O. obscura tiene un S6 con el ápice apenas ligeramente truncado y fue codificado como " 0 "], 1 = ampliamente redondeado [Fig. 9], $2=$ terminando en punta [Figs. 7 y 8]. 17) Forma del grádulo del S6: 0 = recto [Fig. 8], 1 = cóncavo y formando lóbulos laterales [Fig. 64, 65]. 18) Forma de los gonostilos: $0=$ digitiformes (Fig. 57), $1=$ lanciformes (adelgazándose hacia la punta, Fig. 58), 2 = tuberculiformes [como en las Figs. 18 y 27 de Michener (1990)]. 19) Color de los pelos del T6: $0=$ negro, $1=$ amarillo. 20) Distancia interocelar: $0=$ corta [menor que distancia ocelorbital], $1=$ larga [igual o mayor que la distancia ocelorbital]. 21) Color del mesoescutelo: $0=$ café oscuro a negro, $1=$ amarillo. 22) Color del metasoma: 0 = café oscuro a negro, 1 = amarillo a ferrugíneo claro. 23) Margen medioapical del labro: 0 = bilobulada, $1=$ proyectada, $2=$ recta.

\section{Tabla 1}

Matriz de los caracteres usados en el análisis cladístico de la filogenia interna de Oxytrigona. Partamona peckolti y Trigona amalthea fueron usados como grupos externos. Los caracteres son explicados en el texto. Los estados de caracter que no pudieron ser observados porque no se tuvo acceso a los machos, fueron codificados como (-).

\begin{tabular}{lllllllllllllllllllllllllllllll}
\hline Especie & 1 & 2 & 3 & 4 & 5 & 6 & 7 & 8 & 9 & 10 & 11 & 12 & 13 & 14 & 15 & 16 & 17 & 18 & 19 & 20 & 21 & 22 & 23 \\
\hline P. peckolti & 0 & 1 & 0 & 0 & 1 & 0 & 1 & 1 & 0 & 0 & 1 & 1 & 0 & 1 & 0 & 2 & 0 & 2 & 0 & 1 & 0,1 & 0 & 2 \\
T. amalthea & 0 & 1 & 0 & 0 & 0 & 1 & 1 & 1 & 0 & 0 & 0 & 0 & 1 & 1 & 0 & 2 & 0 & 0 & 0 & 0 & 0,1 & 0 & 1 \\
O. chocoana & 1 & 0 & 1 & 1 & 1 & 0 & 0 & 0 & 1 & 0 & 0 & 0 & - & 0 & 0 & 1 & 0 & 1 & 0 & 1 & 0 & 0 & 0 \\
O. daemoniaca & 1 & 0 & 1 & 1 & 1 & 0 & 0 & 0 & 1 & 0 & 0 & 0 & 1 & 0 & 0 & 1 & 1 & 1 & 1 & 1 & 0,1 & 1 & 0 \\
O. flaveola & 1 & 0 & 1 & 1 & 1 & 0 & 1 & 0 & 0 & 0 & 0 & 1 & - & 1 & 1 & 2 & 1 & 1 & 0 & 0 & 1 & 1 & 2 \\
O. ignis & 1 & 0 & 1 & 1 & 1 & 0 & 0 & 0 & 0 & 0 & 0 & 0 & - & 1 & 0 & 1 & 1 & 1 & 0 & 0 & 0 & 0 & 2 \\
O. huaoranii & 1 & 0 & 1 & 1 & 1 & 0 & 1 & 0 & 0 & 0 & 0 & 1 & - & 1 & 1 & 0 & 1 & 0 & 1 & 0 & 1 & 1 & 2 \\
O. mediorufa & 1 & 0 & 1 & 1 & 1 & 0 & 1 & 0 & 0 & 0 & 0 & 0 & 1 & 1 & 1 & 1 & 0 & 1 & 1 & 0 & 1 & 1 & 2 \\
O. mellicolor & 1 & 0 & 1 & 1 & 1 & 0 & 1 & 0 & 0 & 0 & 0 & 0 & 1 & 1 & 1 & 0 & 0 & 0 & 1 & 0 & 1 & 1 & 2 \\
O. mulfordi & 1 & 0 & 1 & 1 & 1 & 0 & 1 & 0 & 0 & 1 & 0 & 1 & 0 & 1 & 1 & 1 & 0 & 1 & 1 & 1 & 1 & 1 & 0 \\
O. obscura & 1 & 0 & 1 & 1 & 1 & 0 & 1 & 0 & 0 & 1 & 0 & 1 & 0 & 1 & 0 & 0 & 1 & 0 & 0 & 1 & 0 & 0 & 2 \\
O. tataira & 1 & 0 & 1 & 1 & 1 & 0 & 0 & 0 & 0 & 1 & 0 & 1 & 1 & 1 & 0,1 & 0 & 0 & 0 & 0,1 & 1 & 0,1 & 1 & 0 \\
O. isthmina & 1 & 0 & 1 & 1 & 1 & 0 & 1 & 0 & 0 & 0 & 0 & 1 & 1 & 1 & 1 & 0 & 0 & 0 & 1 & 0 & 1 & 1 & 2 \\
\hline
\end{tabular}


Cladograma. Un solo árbol fue obtenido del análisis de los caracteres mencionados arriba, en donde $O$. obscura aparece como la especie hermana de todas las otras especies de Oxytrigona (Fig. 66). Cuando se excluyen todos los caracteres de coloración del análisis (caracteres $10,15,19,21$ y 22), también se obtiene un solo árbol $(\mathrm{L}=33, \mathrm{CI}=63, \mathrm{RI}=70)$ en donde $[O$. daemoniaca + O. chocoana $]$ y $[O$. tataira $+O$. mulfordi $]$ aparecen como clados hermanos, apoyados por una sinapomorfia (23-0]) y una homoplasia (20-1), con cada una de las especies restantes basal a cada clado formado subsecuentemente por la especie anterior.

\section{DISCUSIÓN}

Camargo (1984) reconoció, tentativamente, dos grupos de especies dentro de Oxytrigona basado en la coloración oscura (grupo mulfordi: O. mulfordi y $O$. obscura; Fig. 56) o clara (grupo tataira, incluyendo el resto de las especies; Fig. 55) de la celda marginal del ala anterior. Nuestro análisis cladístico sugiere que estos grupos no son monofiléticos (Fig. 66), aun cuando todos los caracteres de coloración son excluidos del análisis (caracteres 10, 15, 19, 21 y 22). Sin embargo, la mayoría de los clados están apoyados por pocos caracteres, y casi todos son de un solo sexo (obrera); además, todavía hay un buen número de especies en Suramérica que son nuevas para la ciencia (J. M. F. Camargo, com. pers., Gonzalez \& Roubik, obs. pers.),

y los machos de algunas especies todavía no se conocen. Por lo tanto, los resultados de este análisis filogenético son preliminares.

Uno de los hallazgos más interesantes de nuestro trabajo, fue la variación en la forma del grádulo y del margen distal del S6 de la obrera (Figs. 61-65). Estos caracteres morfológicos no han sido usados en la sistemática de Meliponini y, en general, son raramente incluidos en estudios filogenéticos de abejas (Packer 2004). El descubrimiento de estos caracteres es importante porque, al igual que en otros géneros de meliponinos (e.g., Partamona Schwarz, 1939, Pedro \& Camargo 2003), las obreras de Oxytrigona son morfológicamente homogéneas y los machos, con una mayor diversidad morfológica, son raramente colectados. La diversidad morfológica del S6 en Oxytrigona, también sugiere que valdría la pena estudiar esta estructura en otros géneros de Meliponini.

Otros caracteres, como la curvatura de la proyección media del S7 del macho (e.g., Figs. 43-46), la forma del margen distal de la tibia posterior de la obrera (e.g., Figs. 1, 3 y 5), y la unión de la vena basal con cu en el ala anterior (coincidente o no), también podrían ser de utilidad filogenética; sin embargo, no los incluimos porque fue difícil establecer categorías discretas, o simplemente porque fueron muy variables (e.g., la unión de la vena basal con cu). También, otros caracteres como la forma del basitarso posterior de la obrera podrían dividirse en estados de caracter mucho más finos que los usados por nosotros. 


\section{Clave para las obreras de Oxytrigona}

* Nota: El estatus taxonómico de estas especies, como por ejemplo el de $O$. tataira, todavía es dudoso (e.g., Schwarz 1948, Camargo 1984). Varias de las especies sin describir de Suramérica pueden ser provisionalmente identificadas con esta clave.

1. Ala anterior con el ápice de la celda radial y toda la celda marginal oscurecida, venas y

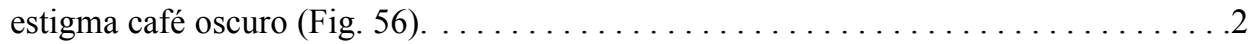

- Ala anterior con el ápice de la celda radial y celda marginal no oscurecida (Fig. 55), hialino o ligeramente coloreado de amarillo, venas y estigma amarillo a

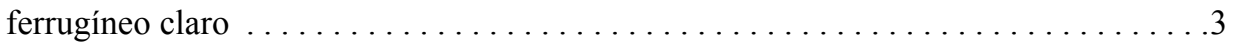

2(1). Cuerpo predominantemente amarillo o anaranjado, pelos de la cabeza y mesosoma ferrugíneos ........................ mulfordi (Schwarz, 1948)

- Cuerpo predominantemente café oscuro a negro, solo la mitad inferior de la cara pálida; pelos de la cabeza y mesosoma negros . . . . . . . . . . . O. obscura (Friese, 1900)*

3(1). Mesoescuto predominantemente amarillo o anaranjado, con o sin manchas negras a cada

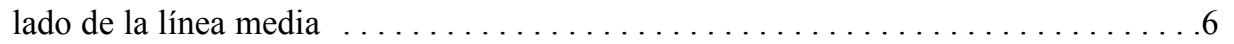

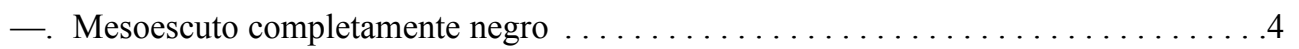

4(3). Basitarso posterior más estrecho en la base que en el ápice, margen posterodistal ampliamente redondeado (Figs. 2, 4); ancho de la cabeza: $\leq 2.3 \mathrm{~mm}$; F2 con un pelo

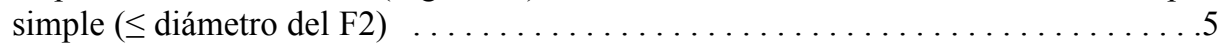

- Basitarso posterior no conspicuamente estrecho en la base, borde posterodistal proyectado en un ángulo, no ampliamente redondeado; ancho de la cabeza: $\geq 2.5 \mathrm{~mm} ; \mathrm{F} 2$ sin pelo ............................ ignis Camargo, 1984

5(4). Área superior de la cara, todo el mesosoma y patas negras; resto de la cara y metasoma amarillo a ferrugíneo claro, contrastando con el resto del cuerpo ..... O. daemoniaca

- Cuerpo predominantemente oscurecido, incluyendo la cara y metasoma (Chocó

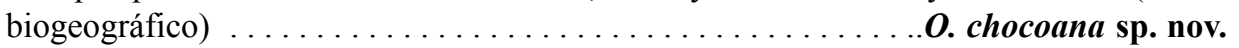

6(3). S6 con el margen distal truncado (Figs. 19-21); mesoescuto completamente amarillo, sin manchas negras; patas, incluyendo coxas y trocánteres, completamente amarillos a

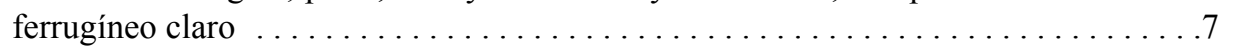

- S6 con el margen distal no truncado, redondeado o terminando en punta (Figs. 9, 65); mesoescuto con una mancha oscura a cada lado de la línea media (tamaño y forma variable); fémur, tibia y basitarsos de todas las patas café oscuros a completamente

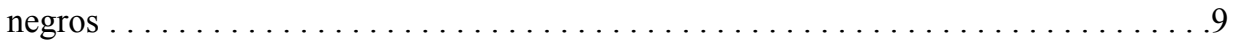

7(6). Fémur anterior corto ( $\leq 4 \mathrm{x}$ más largo que ancho; Fig. 17); ancho de la cabeza: $\leq 2.4 \mathrm{~mm}$

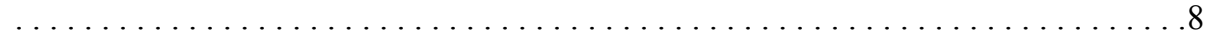

-. Fémur anterior mucho más largo ( $\geq 4.1 \mathrm{x}$ más largo que ancho; Fig. 18); ancho de la cabeza: $\geq 2.5 \mathrm{~mm} \ldots \ldots \ldots \ldots \ldots \ldots \ldots \ldots \ldots \ldots \ldots \ldots \ldots \ldots \ldots \ldots \ldots \ldots$. mellicolor

8(7). Fémur anterior con el borde inferior fuertemente carenado; base del propódeo estriada (Oriente del Ecuador) . ........................ huaoranii sp. nov.

- Fémur anterior con el borde inferior no carenado; base del propódeo lisa, sin estrías (Darién, Panamá) 
9(6). Mesoescuto con las manchas extendiéndose desde el margen anterior hasta la axila; lados del mesosoma y patas ennegrecidas (sur de México a El Salvador) ..........

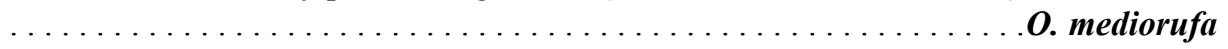

- Manchas del mesoescuto variables en tamaño y longitud, no alcanzando el margen anterior del mesoescuto; coloración de las patas variables (Sur América) . . . . . . . 10

10(9). Basitarso posterior con el margen posterodistal proyectado en un ángulo; S6 con el margen distal terminando en punta (Fig. 65) . . . . . . . . . . . . . . . . . ...................................... flaveola (Friese, 1900)*

—. Basitarso posterior con el margen posterodistal suavemente redondeado; S6 con el

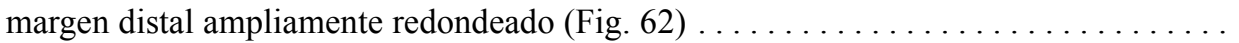
$\ldots \ldots \ldots \ldots \ldots \ldots \ldots \ldots \ldots \ldots \ldots \ldots \ldots \ldots \ldots \ldots \ldots \ldots$ tataira $($ Smith, 1863)*

\section{AGRADECIMIENTOS}

A todos los curadores de las colecciones mencionados arriba, especialmente a G. Nates, C.D. Michener y J.M.F. Camargo por el envío de machos de O. obscura y O. tataira; J. Rozen por el préstamo de los holotipos de $O$. mediorufa, O. mulfordi y $O$. flaveola; C. Rassmusen por el préstamo de los machos de $O$. mediorufa y $O$. mulfordi; dos evaluadores anónimos, R. Ayala, y A. Smith por sus comentarios y discusiones que ayudaron a mejorar el manuscrito. Apoyo financiero para VG fue obtenido a través de los fondos generales de investigación de la Universidad de Kansas y el proyecto US-Israel Binational Science Foundation grant 2000259 (D. Smith \& Y. Lubin).

\section{LITERATURA CITADA}

Ayala, R.T. 1999. Revisión de las abejas sin aguijón de México (Hymenoptera: Apidae: Meliponini). Fol. Entomol. Mex. 106: 1-123.

Ayala, T., T. Griswold. \& D. Yanega. 1996. Apoidea (Hymenoptera). Cap 27, Pp. 424-454 En: L. Bousquets \& J. Morrone (Eds). Biodiversidad, Taxonomía y Biogeografía de Artrópodos de México. Hacia una sintesis de sus conocimiento. Instituto de Biología, México.

Baumgartner, D.L. \& D.W. Roubik. 1989. Ecology of necrophilous and filth-gathering stingless bees (Apidae: Meliponinae) of Perú. J. Kans. Entomol. Soc. 62(1): 11-22.

Bernal, R. \& F. Ervik. 1996. Floral biology and pollination of the dioecious palm Phytelephas Seemannii in Colombia: An adaptation to staphylinid beetles. Biotropica 28(4b): 682-696.

Camargo, J.M.F. 1980. O grupo Partamona (Partamona) testacea (Klug): Suas espécies, distribuição e diferenciação geográfica. Acta Amazonica (Suplemento) 10(4): 1-175.

Camargo, J.M.F. 1984. Notas sobre o genero Oxytrigona (Meliponinae, Apidae, Hymenoptera). Bol. Mus. Para. Emílio Goeldi sér. Zool. 1(1): 115-124.

Coloma, L.A. 1986. Contribución para el conocimiento de las abejas sin aguijón (Hymenoptera, Apidae, Meliponinae) de Ecuador. Quito, Monografía. Pontificia Universidad Católica del Ecuador. 
Gonzalez \& Roubik: Especies nuevas y filogenia de las abejas de fuego

Goloboff, P.A. 1993. NoName (NONA), version 1.5.1. Program and documentation, Fundación and Instituto Miguel Lillo, Tucumán, Argentina.

Griswold, T., Parker, F.D. \& P. Hanson. 1995. The Bees (Apidae). Cap 17, Pp. 650-691. En: P. Hanson \& I.D. Gauld (Eds). The Hymenoptera of Costa Rica. Oxford University Press.

Michener, C.D. 1990. Classification of the Apidae. Univ. Kans. Scien. Bull. 54: 75-164.

Michener, C.D. 2007. The Bees of the World. Johns Hopkins University Press, Baltimore, MD. 2da Edición.

Nates-Parra, G. 1983. Abejas de Colombia: I. Lista preliminar de algunas especies de abejas sin aguijón (Hymenoptera: Apidae: Meliponinae). Rev. Biol. Trop. 31(1): 155-158.

Nates-Parra, G. 1996. Abejas sin aguijón (Hymenoptera: Meliponinae) de Colombia. Pp. 181-268. En: G. Amat, G. Andrade \& F. Fernandez (Eds). Insectos de Colombia: Estudios escogidos. Universidad Javeriana y Academia Colombiana de Ciencias Exactas, Físicas y Naturales, Bogotá, Colombia.

Nates-Parra, G. \& O.I. Cepeda. 1983. Comportamiento defensivo en algunas especies de meliponinos colombianos (Hymenoptera: Meliponinae). Bol. Dep. Biol. 1(5): 65-82.

Nixon, K.C. 1999. WINCLADA, version 0.9.99tuc.13, beta. Cornell University, Ithaca, New York.

Packer, L. 2004. Morphological variation in the gastral sterna of female Apoidea (Insecta: Hymenoptera). Can. J. Zool. 82: 130-152.

Pedro, S.R.M. \& J.M.F. Camargo. 2003. Meliponini neotropicais: o genero Partamona Schwarz, 1939 (Hymenoptera, Apidae). Rev. Bras. Entomol. 47(Supl. 1): 1-117.

Pereboom, J.J.M. \& J.C. Biesmeijer. 2003. Thermal constraints for stingless bee foragers: the importance of body size and coloration. Oecologia 137: 42-50.

Rinderer, T.E., Blum, M.S., Fales, H.M., Bian, Z., Jones, T.H., Buco, S.M., Lancaster, V.A., Danka, R.G., \& D.F. Howard. 1988. Nest plundering allomones of the fire bee, Trigona (Oxytrigona) mellicolor. J. Chem. Ecol. 14: 495-501.

Roubik, D.W. 1983. Nest and colony characteristics of stingless bees from Panamá (Hymenoptera: Apidae). J. Kans. Entomol. Soc. 56(3): 327-355.

Roubik, D.W. 1989. Ecology and natural history of tropical bees. Cambridge University Press, Cambridge, UK.

Roubik, D.W. 1992. Stingless Bees: A guide to Panamanian and Mesoamerican species and their nests (Hymenoptera: Apidae: Meliponinae). Cap. 13, Pp. 495-524. En: D. Quintero $\&$ A. Aiello (Eds). Insects of Panama and Mesoamerica. Selected Studies. Oxford University, UK.

Roubik, D.W. \& H. Wolda. 2001. Do competing honey bees matter? Dynamics and abundance of native bees before and after honey bee invasion. Popul. Ecol. 43: 53-62.

Roubik, D.W., Smith, B.H. \& R.G. Carlson. 1987. Formic acid in caustic cephalic secretions of stingless bee, Oxytrigona (Hymenoptera: Apidae). J. Chem. Ecol. 13(5): 1079-1086.

Schwarz, H.F. 1948. Stingless bees (Meliponidae) of the Western Hemisphere. B. Am. Mus. Nat. Hist. 90: 1-546. 
Schwarz, H.F. 1949. The stingless bees (Meliponidae) of Mexico. Sobretiro de los anales del Instituto de Biología 20(1-2): 357-370.

Vergara. C.B., Villa, A.L. \& G. Nates-Parra. 1986. Nidificación de meliponinos (Hymenoptera: Apidae) de la región central de Colombia. Rev. Biol. Trop. 34(2): 181-184.

Villa, A.L. \& C.B. Vergara. 1984. Contribución al estudio de los hábitos de nidificación de algunas especies de abejas nativas sin aguijón (Hymenoptera: Apidae). Scientiae 1(2): $147-163$.

Vit, P., Medina, M., \& M.E. Enríquez. 2004. Quality standard for medicinal uses of Meliponinae honey in Guatemala, Mexico and Venezuela. Bee World 85(1): 2-5.

Wiley, E.O., Siegel-Causey, D., Brooks, D.R., \& V.A. Funk. 1991. The compleat cladist. A primer of phylogenetics procedures. Univ. Kans. Mus. Nat. Hist., Special Publication 19: $1-158$.

Recibido: 3 de noviembre de 2006

Aceptado: 15 de octubre de 2007 